NASA Contractor Report 3202

\title{
Evaluation of a Locally Homogeneous Flow Model of Spray Combustion
}

C-P. Mao, G. A. Szekely, Jr., and G. M. Faeth

GRANT NGR 39-009-077

APRIL 1980 
NASA Contractor Report 3202

\section{Evaluation of a Locally Homogeneous Flow Model of Spray Combustion}

C-P. Mao, G. A. Szekely, Jr., and G. M. Faeth

Pennsylvania State University

University Park, Penusyluania

Prepared for

Lewis Research Center

under Grant NGR 39-009-077

N/SN

National Aeronautics

and Space Administration

Scientific and Technical

Information Office 


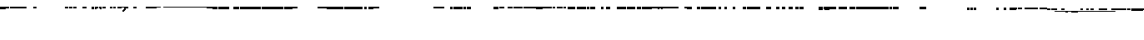


SUMMARY. . . . . . . . . . . . . . . . . . . . . .

NOMENCLATURE

vii

1. INTRODUCTION . . . . . . . . . . . . . . . . 1

2. ATMOSPHERIC PRESSURE COMBUSTION TESTS. . . . . . . . . . 4

2.1 Experimental Apparatus. . .. . . . . . . . . . . . 4

2.2 Instrumentation ................ 4

2.3 Test Conditions................ . . . . 7

3. HIGH PRESSURE COMBUSTION TESTS . . . . . . . . . . . . . 7

3.1 Experimental Apparatus. . . . . . . . . . . . . . . 7

3.2 Instrumentation . . . . . . . . . . . . . . . . 10

3.3 Test Conditions . . . . . . . . . . . . . . . . . . 10

4. THEORETICAL CONSIDERATIONS . . . . . . . . . . . . . . . 10

4.l Description of Model. . . . . . . . . . . . . . . . 10

4.2 Equation of State................. 13

4.2.1 Gaseous Combustion... . . . . . . . . 13

4.2.2 Low Pressure Spray . . . . . . . . . . . . 14

4.2.3 High Pressure Spray. . . . . . . . . . . . . 17

4.3 Governing Equations... . . . . . . . . . . . 22

4.4 Probability Density Function. . . . . . . . . . 23

5. RESULTS ANI DISCUSSION . . . . . . . . . . . . . . 25

5.1 Noncombusting Jets. . . . . . . . . . . . . . . . 25

5.2 Combusting Gas Jet. . . . . . . . . . . . . 30

5.3 Combusting Sprays . . . . . . . . . . . . . . . . 35

5.3.1 Atmospheric Pressure Conditions. . . . . . . 35

5.3.2 High Pressure Conditions... . . . . . . 39

6. CONCLUSIONS. . . . . . . . . . . . . . . . . . . 43

REFERENCES . . . . . . . . . . . . . . . . . . . . . 47 

The objective of the study was to develop and evaluate at locally homogeneous flow (LHF) model of spray combustion, which employs a second-order turbulence model to represent the flow. The LHF approximation is a simplified approach for modeling two-phase flows, where it is assumed that interphase transport rates are infinitely fast. The turbulence model was based on the Reynolds-averaged form of the conservation equations. The equations were solved using the GENMIX computer program. The empirical constants in the turbulence model were fixed by earlier comparisons with noncombusting single-phase constant and variable density jets.

Measurements from this and earlier studies were employed to evaluate the model. The present experiments considered a gaseous $n$-propane flame and an air-atomized n-pentane flame, burning in stagnant air at atmospheric pressure. Profiles of mean velocity and temperature, as well as velocity fluctuations and Reynolds stress, were measured in the flames.

Earlier measurements of high pressure spray combustion were also compared with predictions. Test conditions involved a pressure atomized n-pentane spray, burning in stagnant air at pressures of 3,6 and $9 \mathrm{MPa}$. The latter two pressure conditions involve supercritical combustion of the liquid, i.e., the drops pass through their thermodynamic critical point during the combustion process. These measurements were limited to spray boundaries.

In earlier work, the turbulence model demonstrated good agreement with measurements for single-phase non-combusting flows. This was also the case in the present study. The model predictions of mean and turbulent quantities were also in excellent agreement with the measurements in the gas-fueled flame.

The predictions for the spray at atmospheric pressure were qualitatively correct, however, the rate of development of the flow was overestimated. In view of the good agreement obtained for the gas flame, this indicates an effect of finite rate interphase transport.

The predictions for the high pressure sprays were in fair agreement with the measurements. This is not a very sensitive test of the theory, however, and further theoretical and experimental results are needed to satisfactorily assess the LHF approximation at high pressures.

The advantages of the LHF approach are that the model requires minimal information on injector characteristics, it can easily be run using existing programs for single-phase combustion, and it is generally qualitatively correct. The model provides a lower bound for a spray combustion process, since most practical sprays exhibit some effects of finite interphase transport rates. Thus one application of the model is to assess the maximum potential gain that could be realized by improving injector characteristics in a given application. 



\section{NOMENCLATURE}

a

$\mathrm{C}_{\text {i }}$

C

d

f

g

h

$h_{f g}$

k

$k_{i j}$

$\dot{\mathrm{m}}$

$M_{i}$

$\dot{M}$

$n_{f}, n_{g}$

p

$P(f)$

$r$

$\mathrm{T}$

$\mathrm{u}$

v

$v^{o}$

$x$

$x_{i}$

$\mathrm{Y}_{\mathrm{i}}$ acceleration of gravity

parameters in turbulence model

specific heat

injector diameter

mixture fraction

square of mixture fraction fluctuations

enthalpy

enthalpy of vaporization

kinetic energy of turbulence

binary interaction parameter

mass flow rate

molecular weight of species i

jet momentum

number of moles of liquid and vapor

pressure

probability density function

radial distance

temperature

velocity in axial direction

velocity in radial direction

weighted velocity in radial direction, $\mathrm{Eq}$

axial distance

mole fraction of species $i$

mass fraction of species i 
$v_{i}^{\prime}, v_{i}^{\prime \prime}$

$\rho$

$\sigma_{i}$

$\phi$

$\Omega_{\mathrm{a} 1}, \Omega_{\mathrm{b}_{1}}$

\section{Subscripts}

c

$F_{E}, F_{g}$

$\mathrm{O}_{2}$

N,

sat

o

$\infty$

Supersiripts rate of dissipation of turbulence kinetic energy stoichiometric coefficients, Eq. (1)

density

turbulent Prandt $1 /$ Schmidt number

generic property

parameters in Redlich-Kwong equation of state

centerline quantity

liquid and vapor fuel

oxygen

nitrogen

saturated vapor condition

injector exit condition

ambient condition

time-averaged quant ity

tlutuat ing quant ity. 
Several investigators have considered the development of comprehensive spray combustion models, as a means of reducing cut and try testing during combustor development $(1,2)$. A number of these models attempt to treat most spray phenomena, considering finite rate interphase transport, higher-order turbulence closure, combustion, pollutant production and radiation. Validation of these models has lagged their development, but encouraging progress is being made in obtaining agreement between predictions and measurements $(1,2)$.

Several difficulties are encountered when comprehensive spray combustion models are applied to practical problems. First of all, such models involve a large number of approximations and empirical constants. This provides scope to match given experimental results, but raises questions concerning their a priori predictive capabilities, particularly in view of the limited progress that has been made to validate comprehensive models. A second difficulty involves the need for detailed injector characteristics, information which is rarely available for hot firing conditions. This necessitates the use of additional assumptions concerning injector boundary conditions in most cases.

In this circumstance, simplified models are of value. This investigation considers the development and evaluation of a simplified mode1 based on the locally homogeneous flow (LHF) approximation. The LHF approximation implies that interphase transport rates are infinitely fast. With this approximation, numerical solution of the conservation equations can employ existing general purpose computer codes for gaseous combustion processes, with little modification. The model does not require extensive information on injector characteristics and the number of model constants to be specified is limited in comparison to comprehensive spray models.

Thring and Newby (3) were among the first to suggest the app 1ication of the LHF approximation to sprays. Later work by Newman and Brustowski (4), and Onuma and Ogasawara (5) suggested potential successful use of the method for well atomized sprays, particularly at high pressures. In fact, a number of empirical Diesel combustion models are based on LHF ideas (6). On the other hand, earlier work on evaporating and combusting sprays, also found conditions where the LHF approach was less effective $(7,8)$. However, due to theoretical and experimental uncertainties in these earlier studies, a rational prescription for the range of applicability of the LHF method has not been developed.

The present investigation is an extension of earlier work on the application of the LHF model to evaporating sprays, completed in this laboratory $(9,10)$. The basic turbulent flow theory employs the model described by Lockwood and Naguib (11) for single phase combusting and noncombusting jets. This model was systematically evaluated using 
data from noncombusting single-phase constant and variable density. jets, prior to modification in order to consider evaporating sprays $(9,10)$. When applied to an evaporating Freon 11 spray (Sauter mean diameter (SMD) of $29 \mu \mathrm{m}$ ), effects of finite rate interphase transport were detected. The LHF prediction indicated a more rapidly developing flow than was measured, which resulted in errors in mean velocities and mixture fraction on the order of $20-40 \%$. It was also found that completing drop-1ife-history calculations, using the LHF results to prescribe the ambient conditions of drops in the spray, provided a rational means of theoretically evaluating the LHF prediction for a given application $(9,10)$.

The results of the earlier investigation $(9,10)$ suggested that the LHF approach might still be useful for spray combustion processes, particularly at high pressures. This is due to the fact that combustion is completed downstream of the region where spray evaporation dominates the flow, which tends to reduce the effect of model exrors in the evaporation region when predictions of overall combustion characteristics are desired.

The present extension involved the development of the LHF spray combustion model, with special emphasis on high pressure phenomena where effects of the liquid approaching the thermodynamic critical point must be considered.

The basic configuration that was studied involves noncombusting and combusting single- and two-phase jets in a stagnant media. The evaluation was systematic, considering the following flows, in turn:

1. Noncombusting single- and two-phase jets, using existing measurements in the literature $(9,10,12-17)$.

2. Combusting gas jet employing measurements obtained during the present study. This involved measurements of mean velocity, turbulence quantities and mean temperature, in an $n$-propane jet burning in air at atmospheric pressurc.

3. Combusting spray at atmospheric pressure employing measurements obtained during the present study. This involved measurements of mean velocity and mean gas temperature in an $n$-pentane spray, burning in air at atmospheric pressure.

4. Combusting spray at high pressures. This involved measurements of spray boundaries obtained during an earlier investigation in this laboratory (8). Test conditions involved a burning $n$-pentane spray at pressures of $3.2,6.3$ and $9.4 \mathrm{MPa}$. The latter two test conditions are at sufficiently high pressure that a portion of the drops in the spray reach their thermodynamic critical point during combustion. 
The authors were assisted by $H$. Tamura of the National Aerospace Laboratory, Kakuda Branch, Japan, and A. J. Shearer of the General Motors Research Laboratory, Warren, Michigan. During their stay at the Pennsylvania State University, these individuals contributed significantly to the development of the computer program used in this study. Mr. Shearer also completed the measurements in high pressure combustion sprays that are used in the present investigation. 


\section{ATMOSPHERIC PRESSURE COMBUSTION TESTS}

2.1 Experimental Apparatus. The apparatus and instrumentation for the atmospheric pressure combustion tests were similar to the earlier arrangement employed for tests considering evaporating sprays $(9,10)$. Only a brief discussion is given here, further details can be found in Ref. 10. The same apparatus was used for both gas jet and spray tests.

Figure $I$ is a sketch of the experimental apparatus. For present work, the nozzle was positioned at the bottom of the test strand, injecting upward. The test stand was an area $1.2 \mathrm{~m}$ square and $3 \mathrm{~m}$ high, enclosed with a single thickness of 16 mesh screen. The test stand was located within a room having dimensions $4.0 \mathrm{~m} \times 6.5 \mathrm{~m} \times 3.9 \mathrm{~m}$ high. Combustion products were removed through an exhaust fan located near the ceiling of the test cell.

An air atomizing nozzle was used during the investigation. The nozzle was manufactured by Spraying Systems Company (Mode1 1/4 J 2050 fluid nozzle and 67147 air nozzle). This nozzle was also employed for the results of Refs. 9 and 10. Two traversing mechanisms were used to position the nozzle in a horizontal plane. The nozzle mount could also be moved vertically in several steps, to facilitate profile measurements.

The gas and spray flames were stabilized near the exit of the injector using an array of four hydrogen capillary flames. The flame tubes were mounted in a symmetrical opposed pattern injecting toward the centerline of the injector passage. The flow passages for the hydrogen were slots, $0.4 \mathrm{~mm}$ wide and $2 \mathrm{~mm}$ long, with the long axis parallel to the injector centerline. The lower edge of the slots were $1.8 \mathrm{~mm}$ above the face of the injector. The exit planes of the slots were $6.4 \mathrm{~mm}$ apart.

The gas flow side of the system illustrated in Fig. 1 was employed for air flow to the injector during spray tests, and for the gas jets. The gas flow rates were metered and controlled using a critical flow orifice and pressure regulator combination. Liquid flow rates were controlled by varying the air pressure above the surface of the liquid in the feed tank. Liquid flow rates were measured by timing liquid level changes in a slight gauge. The momentum of the flow was measured by mounting an impact plate attached to a load cell, in front of the injector (10).

\subsection{Instrumentation. Gas velocities were measured using a} single-channel laser Doppler anemometer (LDA). The arrangement of the LDA is illustrated in Fig. 2. This unit employs a helium-neon 1aser, operating in the dual-beam, forward-scatter mode. A frequency shifter is used, so that flow reversals can be detected near the edge of the flow. The signal from the photodetector is processed using a tracker in conjunction with an integrating digital voltmeter. Al1 LDA components are manufactured by Thermo-Systems, Inc. (10). Various velocity components, turbulent fluctuations and the Reynolds stress were obtained by varying the orientation of the crossing laser beams (10). 


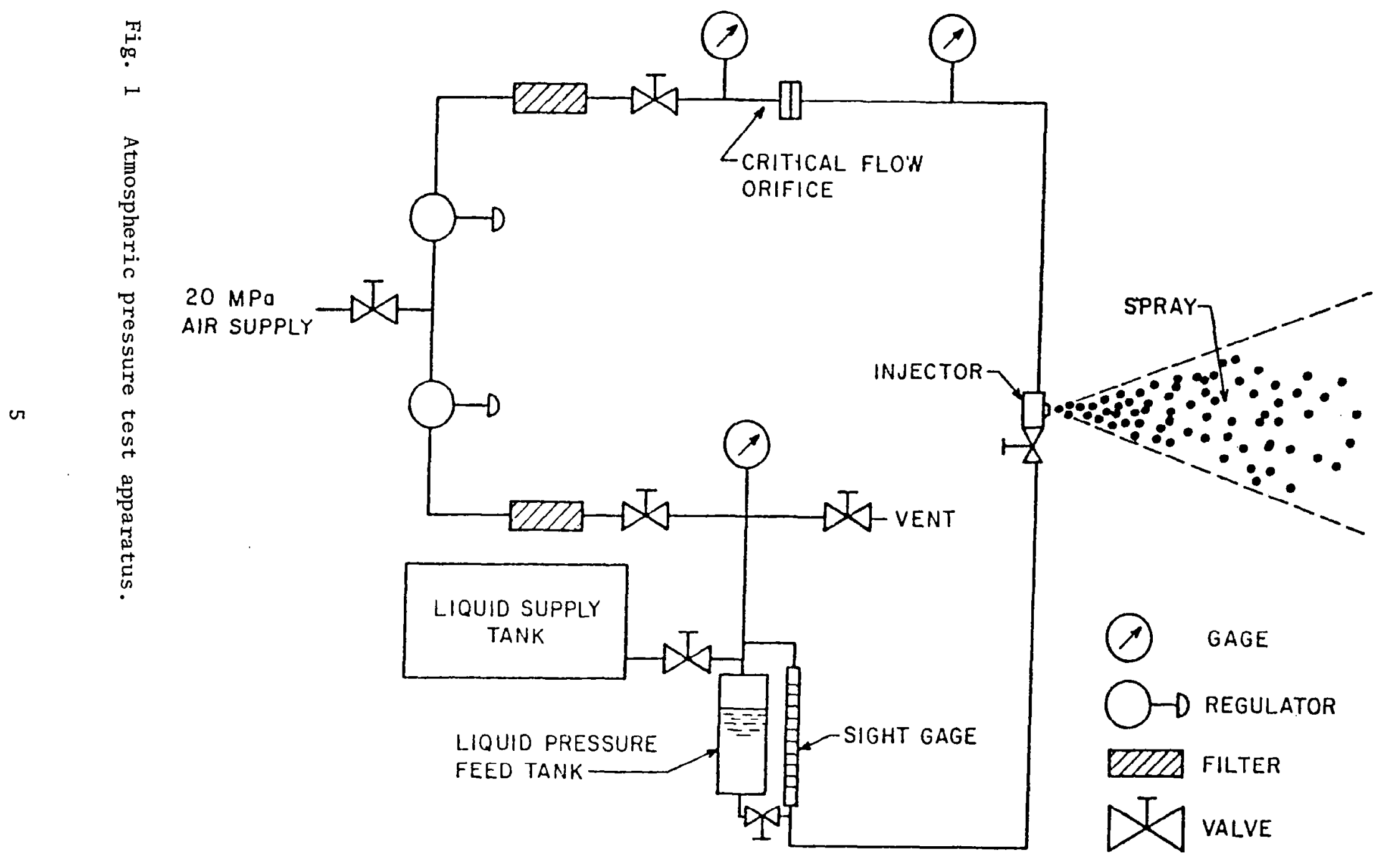




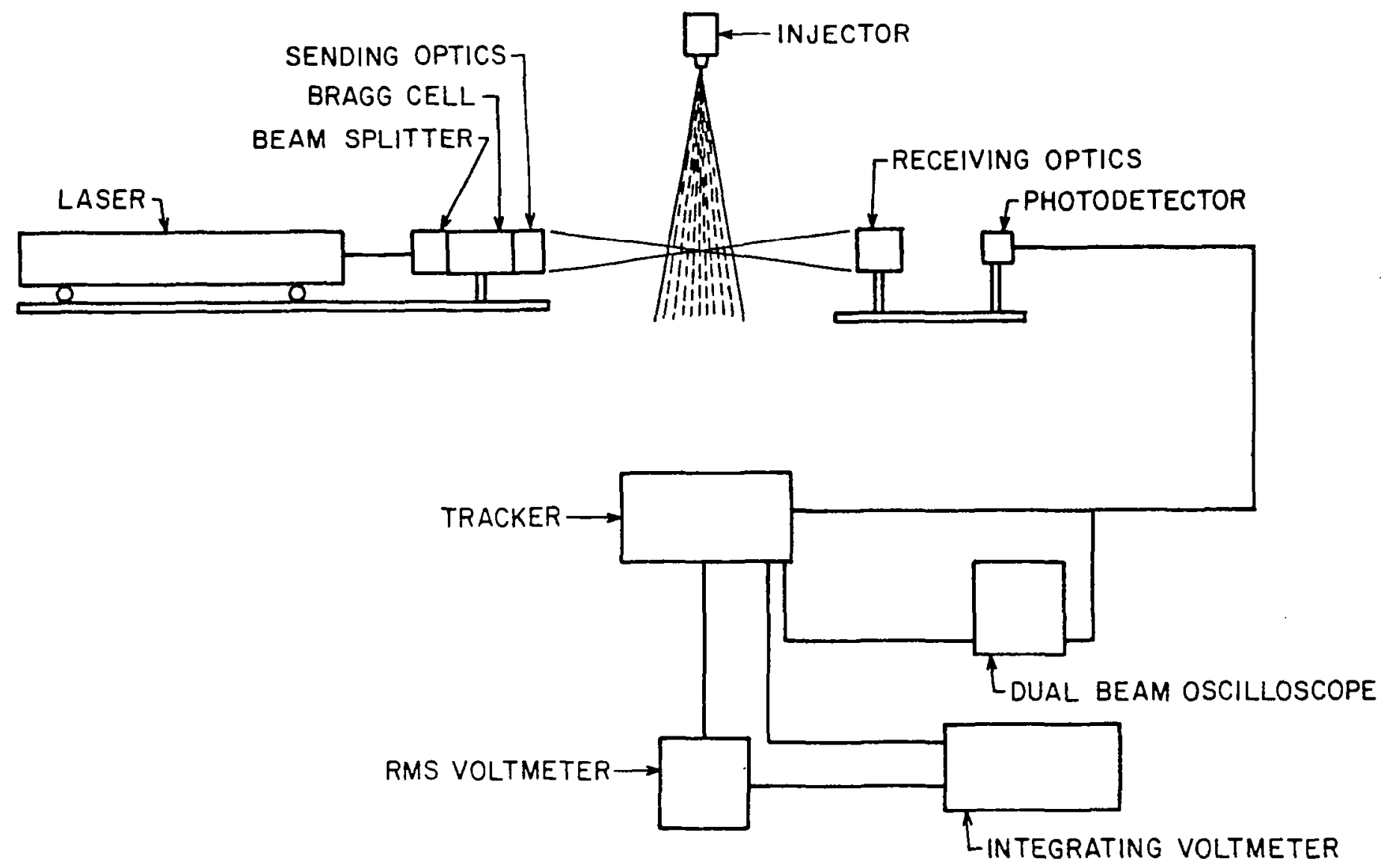

Fig. 2 Schematic diagram of the LDA system for jet and spray measurements. 
The LDA actually measures the velocity of small seeding particles in the flow. The noncombusting flows were seeded in the manner described in Ref. 10. This involved seeding the ambiance with oil particles condensed in the exhaust of a vacuum pump (average particle diameter $0.62 \mu \mathrm{m}$, concentration of $2.8 \times 10^{10}$ particles $/ \mathrm{m}^{3}$ ). The combusting flows could not be handled in this manner due to their large air entrainment rates. In this case soot formed in the flames provided a portion of the seeding particles (in the region of combustion). In order to avoid biasing the signal, seeding was also added to the air, in the rogion where measurcments werc being made. These seeding particles were produced as condensed oil vapor in an air stream passing through an oil heater.

Mean gas temperatures were measured using a $\mathrm{Pt} / \mathrm{Pt}-10 \% \mathrm{Rh}$ thermocouple. For tests in the gas fueled flame, the thermocouple was constructed of $50 \mu \mathrm{m}$ diameter wires, mounted in turn on heavier leads. The radiation correction for this thermocouple was less than $35 \mathrm{C}$ over the test range. A correction for radiant heat loss has not been applied to the data.

Temperature measurements in sprays are complicated due to effects of drop impingement. The arrangement used in the present work is illustrated in Fig. 3. The thermocouple junction was constructed of $50 \mu \mathrm{mPt} / \mathrm{Pt}-10 \% \mathrm{Rh}$ wires. The junction is shielded from direct impact by most drops using an upstream barrier (collection efficiency of unity for drop diameters greater than $10 \mu \mathrm{m}$ at most points in the flow). The radiation correction for this design has not been established as yet, and the data reported are not corrected for radiation. Checking the measurements of the shielded probe against those of the bare wire probe, in the gas flame, yielded agreement within $10 \mathrm{C}$. This suggests that radiation errors were similar for both units.

Tests with a dense gas, $\mathrm{SF}_{6}$, were repeated in order to check present experimental results with the measurements of Ref. 10. Gas compositions in this case were obtained by isokinetic sampling and analysis using a gas chromatograph(10).

2.3 Test Conditions. The test conditions considered in the study are summarized to Table 1 . Tests with air and sulphur hexafluoride were employed to check present experimental techniques against the results reported in Refs. 9 and 10 . The combusting flows represent new test conditions, considered during this investigation.

The gases used in the study were obtained from Matheson Gas Products (air, 99.8 percent purity; sulphur hexafluoride, 99.8 percent purity; n-propane, 99 percent purity). The n-pentane was obtained from Fisher Scientific Company (98 percent purity).

\section{HIGH PRESSURE COMBUSTION TESTS}

3.1 Experimental Apparatus. These tests were completed earlier and are fully described in Ref. 8. Only a brief description of the apparatus will be given here, in order to indicate the nature of the measurements. 


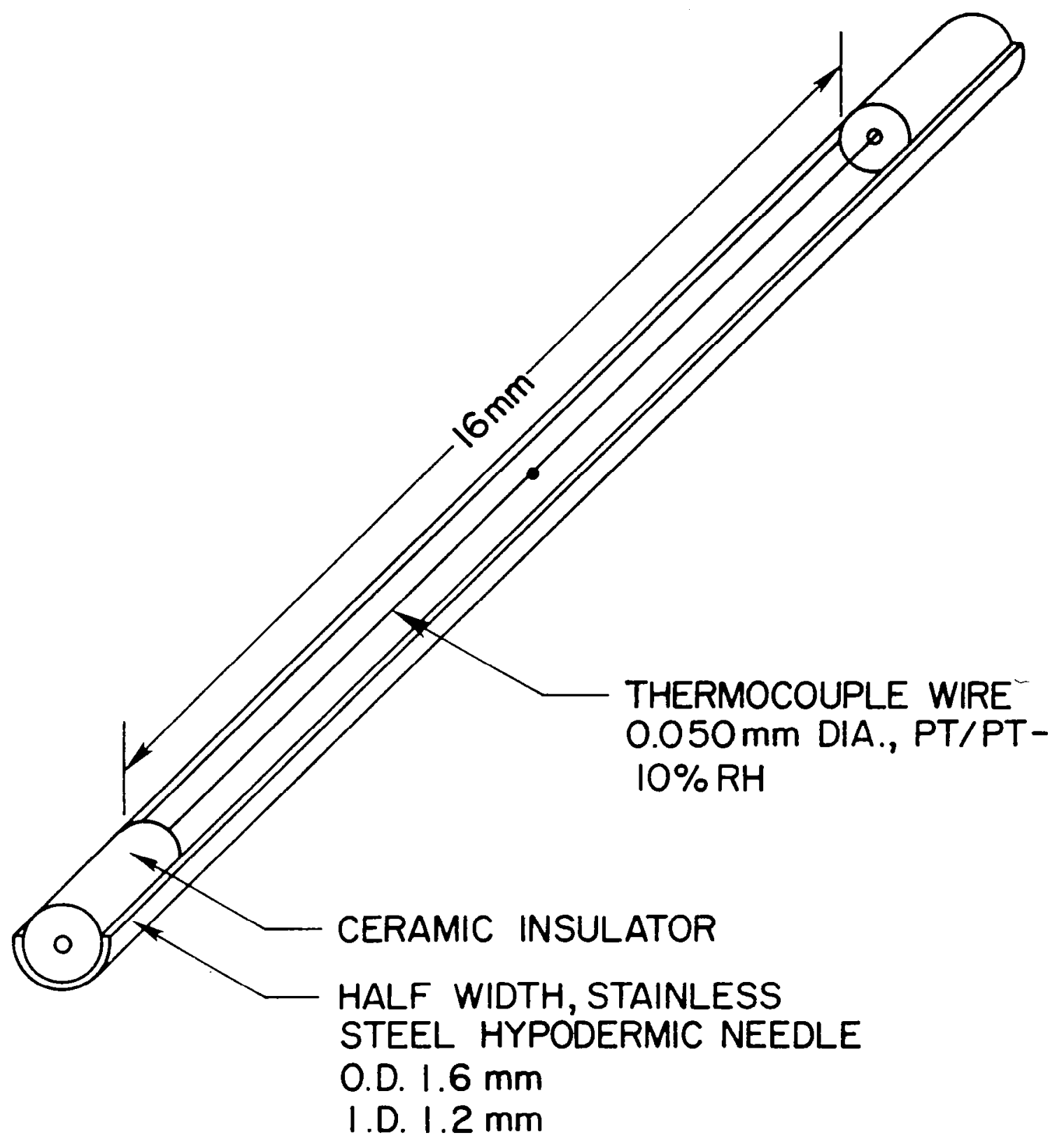

Figure 3. Sketch of the spray temperature probe. 


\section{Tab1e 1}

Summary of Test Conditions ${ }^{a}$

\begin{tabular}{|c|c|c|c|c|}
\hline Case & $\begin{array}{c}\text { Constant } \\
\text { Density } \\
\text { Jet }\end{array}$ & $\begin{array}{c}\text { Variable } \\
\text { Density } \\
\text { Jet }\end{array}$ & $\begin{array}{l}\text { Combusting } \\
\text { Gas Jet }\end{array}$ & $\begin{array}{l}\text { Combusting } \\
\text { Spray }\end{array}$ \\
\hline Injector Fluid & air & $\begin{array}{l}\text { Sulphur } \\
\text { Hexa- } \\
\text { fluoride }\end{array}$ & Propane & $\begin{array}{l}\text { n-Pentane } \\
\text { and air }\end{array}$ \\
\hline \multicolumn{5}{|l|}{$\begin{array}{l}\text { Injector Flow Rates } \\
(\mathrm{g} / \mathrm{s})\end{array}$} \\
\hline Gas & 0.225 & 0.323 & 0.176 & 0.080 \\
\hline Liquid & 0 & 0 & 0 & 0.35 \\
\hline \multicolumn{5}{|l|}{$\begin{array}{l}\text { Injector Pressures } \\
(\mathrm{kPa})\end{array}$} \\
\hline Gas & 131.7 & 131.7 & 131.0 & 120.6 \\
\hline Liquid & - & - & - & 137.9 \\
\hline $\begin{array}{l}\text { Jet Momentum } \\
(\mathrm{mN})\end{array}$ & 38.7 & 15.8 & 15.6 & 5.0 \\
\hline $\begin{array}{l}\text { Initial Velocity } \\
(\mathrm{m} / \mathrm{s})\end{array}$ & 171.9 & 49.1 & 88.7 & 11.6 \\
\hline $\begin{array}{l}\text { Sauter Mean } \\
\text { Diameter } \\
(\mu \mathrm{m})\end{array}$ & - & - & - & 35 \\
\hline
\end{tabular}

ambient temperature and pressure, $296 \mathrm{~K}, 97 \mathrm{kPa}$; injector inside diameter, $1.194 \mathrm{~mm}$.

$\mathrm{b}_{\text {Hydrogen }}$ jet stabilized, total hydrogen flow rate of $1.26 \times 10^{-4} \mathrm{~g} / \mathrm{s}$.

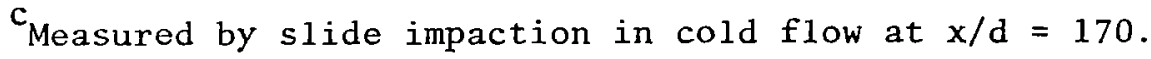


A sketch of the apparatus appears in Fig. 4. The injector opȩrates within a windowed pressure vessel having a volume of 9000 $\mathrm{cm}^{3}$, and rated to $10 \mathrm{MPa}$. High pressure air for the system was provided by a filtered shop air supply.

The injector was only operated for a short period of time, in order to limit oxygen consumption within the test chamber. The fuel for the test was contained in a tube loop just upstream of the injector. Injection was accomplished by subjecting the upstream side of the loop to air at higher pressure than the chamber, by opening a solenoid valve. Injection terminated when all the fuel in the loop passed out of the injector. The total quantity of fuel was limited to $4 \mathrm{~m} 1$ for all tests. The injector had a straight hole injection passage (Spray Systems Co., 0.000009 solid stream tip).

The spray was ignited and stabilized by a heated coil of nichrome wire located near the injector exit. Dark field photographs confirmed that the flame was attached back to the injector.

3.2 Instrumentation. Chamber pressures were measured with three Heise absolute pressure gauges having maximum pressures of $2.1,10.3$ and $51.7 \mathrm{MPa}(300,1500$ and $7500 \mathrm{psia})$ and 0.1 percent accuracy. The injector pressure drop was set with a differential pressure gauge.

The spray was photographed with a Photosonic 1-B motion picture camera, employing 16 Im Kodak Plux-X reversal filll. Spray boundaries were obtained from shadowgraphs, using a mercury arc background light. The field of view had an area of approximately $1.25 \mathrm{~cm}^{2}$. Therefore, the injector had to be moved in order to cover the entire length of the process. The photographs were analyzed, frame by frame, using a microfilm viewer.

3.3 Test Conditions. The test conditions considered in the study are summarized in Table 2. The fuel was obtained from Fisher Scientific Company, 98 percent minimum purity.

\section{THEORETICAL CONSIDERATIONS}

4.1 Description of Mode1. The theoretical model considers a steady, axisymmetric, turbulent $j$ et in an infinite stagnant media. The flows considered during the theoretical portion of this study are as follows:

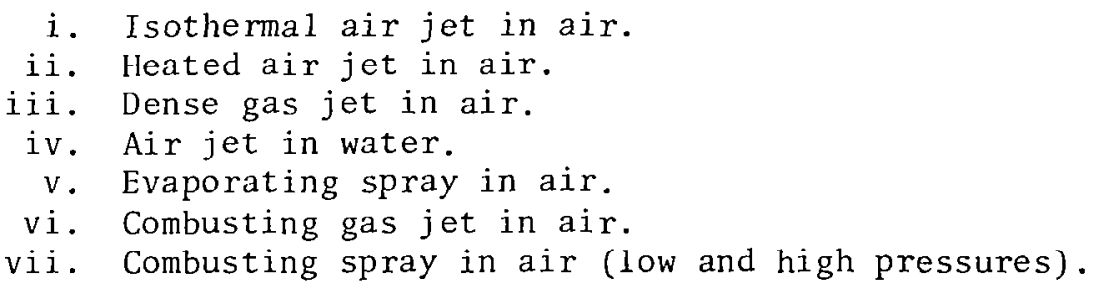

Flows $i-v$ have been discussed earlier $(9,10)$. Flows vi and vii are treated in this investigation. 


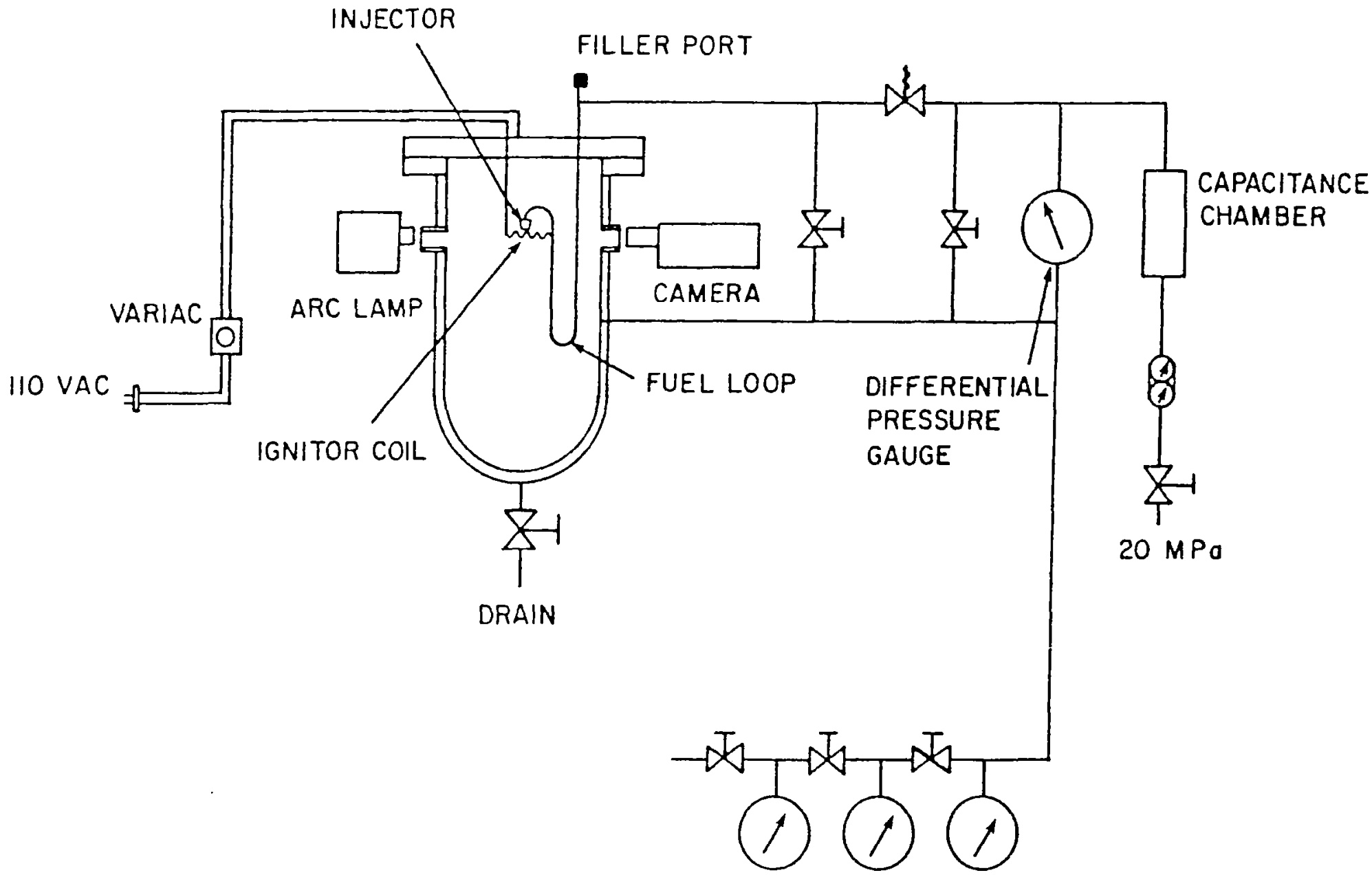

Fig. 4 Sketch of the high pressure spray combustion apparatus. 


\section{Table 2}

Summary of High Pressure Spray Combustion Test Conditions

\begin{tabular}{lc}
$\begin{array}{c}\text { Fuel } \\
\text { Environment }\end{array}$ & $\begin{array}{c}\text { n-Pentane at } 20-30 \mathrm{C} \\
\text { Aix at 20-30C }\end{array}$ \\
\hline Sauter Mean Diameter ${ }^{a}$ & $28 \mu \mathrm{m}$ \\
Maximum Drop Diameter ${ }^{\mathrm{a}}$ & $79 \mu \mathrm{m}$ \\
Spray Velocity at Injector Exit & $69 \mathrm{~m} / \mathrm{s}$ \\
Injector Pressure Drop & $2.67 \mathrm{MPa}$ \\
Injector Diameter & $0.2 \mathrm{~mm}$ \\
Test Pressures & $3.2,6.3,9.4 \mathrm{MPa}$ \\
\hline
\end{tabular}

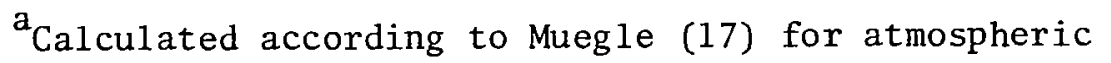
pressure ambient conditions. 
The turbulent flow analysis follows procedures developed by Lockwood and coworkers $(11,18)$. References 9 and 10 consider the application of this analysis to two-phase jets, employing the LHF approximation. The contribution of the present investigation involves extension to combusting flows and high pressure conditions. This effort largely involves construction of appropriate equations of state, relating mixture fraction (fraction of mass at a point which originated from the injector) to other physical properties of the flow (density, composition, temperature, etc.).

The LIF approximation for two-phase flows implies that the velocities of both phases are the same, and that both phases are in thermodynamic equilibrium, at each point in the flow. This means that the temperature of both phases is the same and that phase equilibrium is maintained. In combusting flows, we also assume that chemical equilibrium is maintained, as we 11.

Under the assumption of LHF flow, the remainder of the analysis parallels models for single-phase flows. Typical of analyses of low Mach number jets, the boundary layer approximations are used and viscous dissipation and mean kinetic energy are neglected. Radiation was also neglected. Similar to earlier studies $(11,18)$ it is also assumed that the exchange coefficients of species and heat are the same.

The assumption of equal exchange coefficients for all species and heat implies that the mixture fraction, $f$, is a conserved property of the flow. In combination with the other assumptions of the analysis, this implies that the properties at each point in the flow correspond to the thermodynamic equilibrium state attained when an amount $f$ of injector fluid and (1-f) of ambient fluid, at their initial states, are adiabatically mixed at the ambient pressure of the jet.

The flow model is based on a second-order turbulence mode1, employing Reynolds-averaged conservation equations $(10,11,18)$. Transport of mean quantities is given by conservation equations for mass, momentum and mixture fraction. Turbulence characteristics are obtained by solving model transport equations for turbulent kinetic energy, k, dissipation, $\varepsilon$, and concentration fluctuations, $g$. In conjunction with an assumed functional form for the probability density function for mixture fraction, and the local values of $f$ and $g$, the equation of state yields all other physical properties of the flow. Buoyancy is considered in the mean conservation equations; however, its effect on turbulence quantities is ignored.

4.2 Equation of State. Development of the equations of state for the noncombusting flows was described earlier $(9,10)$. Only the combusting flows are considered in the following.

4.2.1 Gaseous Combustion. In this case, the calculation of the equation of state involves determination of the equilibrium state attained when the injector and ambient gases are mixed in 
different proportions. This problem corresponds to a conventional adiabatic flame calculation. In the present case, dissociation and variable thermodynamic properties were considered. All gases are assumed to be ideal. The calculations were completed using the package computer program CEC-72 (19). This program incorporates the JANNAF thermochemical properties for the combustion gases.

The results of the calculations for the combusting propane jet considered in the experiments (Table 1) are illustrated in Fig. 5. This plot provides the temperature, density, and mass fractions of oxygen, nitrogen and propane as a function of mixture fraction.

In constructing an equation of state for a combusting system, some rather arbitrary decisions must be made concerning the extent of equilibration. Low and high mixture fractions are outside the normal flammability limits, and equilibrium calculations predict substantial quantities of soot at high mixture fractions. Throughout this study it was assumed that reaction occurs at all mixture fractions, but soot does not form at temperatures below $1000 \mathrm{~K}$. The effect of these assumptions is greatest near the injector, where high mixture fractions are encountered in the calculations. In the downstream region, where the current measurements were made, the probability of a large mixture fraction appearing in the flow is relatively small.

This conceptual problem could be eliminated by prescribing a probability density function for extent of reaction (20). This approach was not pursued, however, since the assumption of complete chemical equilibrium has been reasonably successful in earlier studies $(18,21)$.

4.2.2 Low Pressure Spray. The equation of state for the low pressure spray was constructed assuming that all gases were ideal. The solubility of the liquid phase for nonfucl gascs was neglected.

In the low mixture fraction region, the equation of state was found using the package computer program, similar to the calculations for a gaseous fuel. At high mixture fractions, the presence of liquid must be considered. In this region, dissociation was ignored, similar to the gas jet computations.

In order to simplify the notation, the discussion of the computations at high mixture fractions will be conducted on a molar basis assuming only liquid fuel leaves the injector. The stoichiometry of the reaction is as follows:

$$
\text { Fuel }+\nu_{\mathrm{O}_{2}}^{\prime} \mathrm{O}_{2}+\nu_{\mathrm{N}_{2}}^{\prime} \mathrm{N}_{2} \rightarrow \Sigma \nu_{i}^{\prime \prime}[\mathrm{I}]
$$

where $v_{\mathrm{O}_{2}}^{\prime}$ and $\nu_{\mathrm{N}_{2}}^{\prime}$ are obtained directly from $f$, given the molecular 


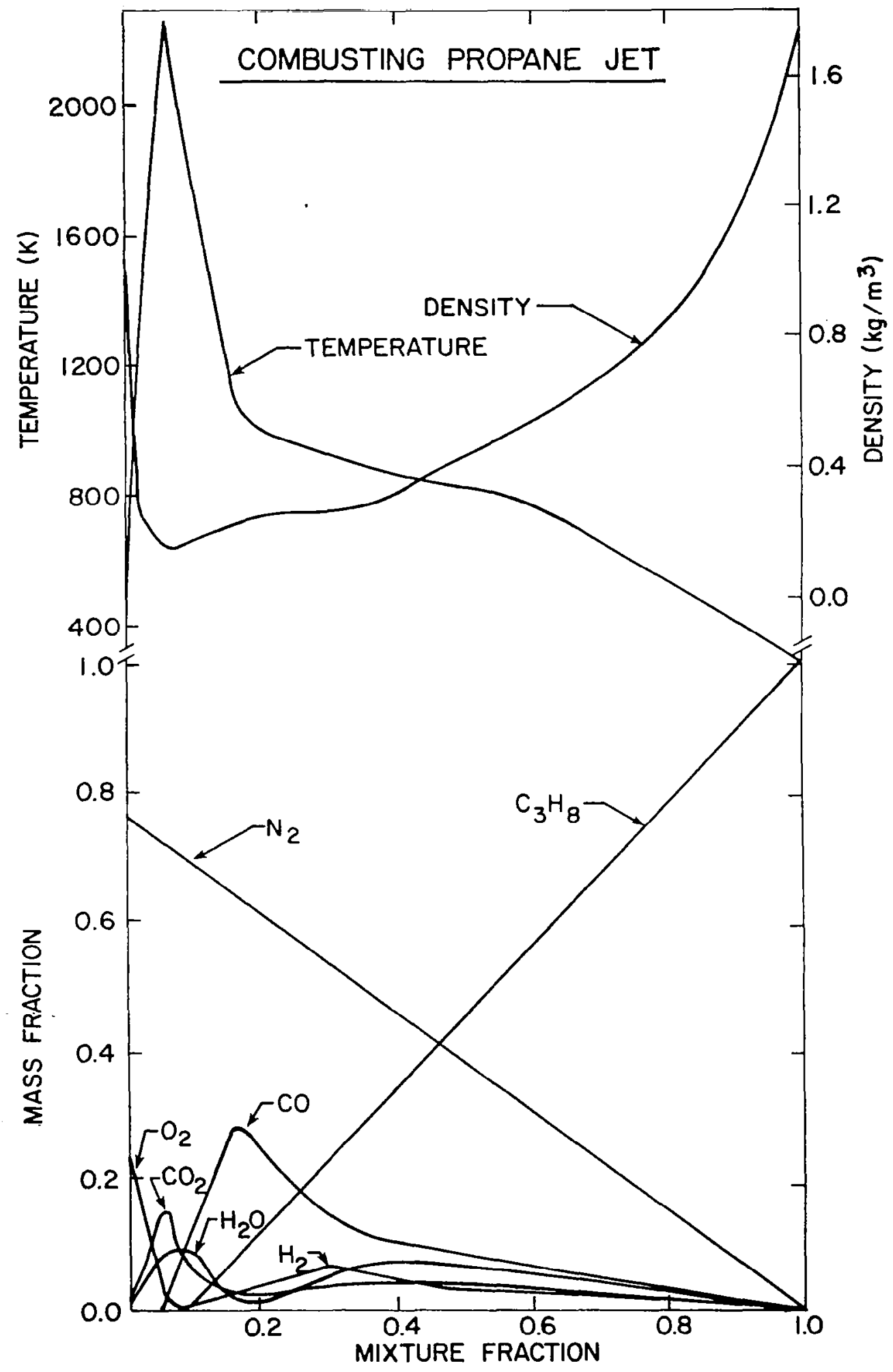

Figure 5. Equation of state for a propane gas jet burning in aix at atmospheric pressure. 
weights of the reactants. At high mixture fractions, fuel appears as both liquid and vapor, $\left(\nu_{\mathrm{Ff}}\right.$ " and $\left.\nu_{\mathrm{Fg}}{ }^{\prime \prime}\right)$. The sum of these quantities is known from Eq. (1). Given the temperature of the fuel-product mixture, the vapor pressure of the liquid provides

$$
\nu_{F g} "=\underset{i \neq l i q u i d}{\left(\Sigma \nu_{i} "\right)} p_{\text {sat }_{F}}(\mathrm{~T}) / \mathrm{p}
$$

where

$$
\mathrm{p}_{\text {sat }_{F}}(\mathrm{~T})
$$

is the vapor pressure of the fuel at the mixture temperature. Conservation of energy yields the following

$$
\mathrm{h}_{\mathrm{Ff}}+\nu_{\mathrm{O}_{2}}^{\prime} \mathrm{h}_{\mathrm{O}_{2}}+\nu_{\mathrm{N}_{2}}^{\prime} \mathrm{h}_{\mathrm{N}_{2}}=\Sigma \nu_{i}{ }^{\prime \prime} \mathrm{h}_{\mathrm{i}}
$$

The values of

$$
\mathrm{h}_{\mathrm{Ff}}, \mathrm{h}_{\mathrm{O}_{2}} \text { and } \mathrm{h}_{\mathrm{N}_{2}}
$$

are known from the prescribed operating condition. Given constitutive equations for the enthalpies of liquid and vapor species, Eqs. (1) $\rightarrow(3)$ are sufficient to solve for all the $v_{i} "$ and the mixture temperature.

In regions where no liquid is present, Eq. (1) gives the composition of all species immediately and Eq. (2) is no longer relevant. The remainder of the solution follows the procedure outlined above. In high temperature regions, dissociation is considered using the CEC-72 program (19).

The $v_{i} "$ yield the mass fractions of the various species, as follows

$$
Y_{i}=\left(v^{\prime \prime M}\right)_{i} / \Sigma v_{j}^{\prime \prime} M_{j}
$$

The mixture density is given by

$$
\rho=\left[\sum Y_{i} / \rho_{i}\right]^{-1}
$$


where the densities of gaseous species are determined from the ideal gas equation of state at the temperature and total pressure of the mixture.

The resulting equation of state for a liquid $n$-pentane jet burning in air, at atmospheric pressure and $300 \mathrm{~K}$, is illustrated in Fig. 6. The low mixture fraction region is similar to the results for gaseous combustion, illustrated in Fig. 5. However, the presence of liquid significantly alters the high mixture fraction region. The mixture temperature varies more slowly than in the region where only gases are present, due to heat of vaporization requirements. The mass fraction of fuel vapor reaches a maximum, at the point where the liquid disappears. The density is a minimum at the stoichiometric mixture ratio, and sharply increases in the region where liquid is present.

4.2.3 High Pressure Spray. At low mixture fractions, the method of finding the equation of state at high pressures involves no changes from the procedure described earlier. In this region, mixture temperatures are sufficiently high so that compressibility effects are small and can be ignored. However, compressibility effects must be considered at high mixture fractions.

Compressibility effects were handled similar to earlier work on high pressure combustion completed in this laboratory (22). This involves employing the Redlich-Kwong equation of state to treat both gas and liquid phases. The fact that a portion of the non-fuel gases is dissolved in the liquid is also considered in the analysis. In order to apply the Redlich-Kwong equation to multicomponent mixtures, mixing rules are needed for several parameters. These were obtained using the method described by Prausnitz and Chueh (23). The formulation of the Redlich-Kwong equation of state and its mixing rules is lengthy and has been reported earlier (24). Therefore, the formulation will not be repeated here. The parameters used in the model, employing the notation of Ref. 24, are sumnarized in Table 3.

The unknowns of this problem are the compositions of the phases,<smiles>[Y][14CH2][14CH2][14CH2][14CH3]</smiles>

the number of moles of liquid and vapor $\mathbf{n}_{\mathbf{f}}, \mathrm{n}_{\mathrm{g}}$ and the temperature. Considering the equilibrium mixture to be composed of fuel, $\mathrm{N}_{2}$, CO and $\mathrm{H}_{2} \mathrm{O}$, we have eleven unknowns, given the mixture fraction and pressure. Stoichiometry, Eq. (1), provides four equations, as follows

$$
x_{i f} n_{f}+x_{i g} n_{g}=v_{i}^{\prime \prime}
$$




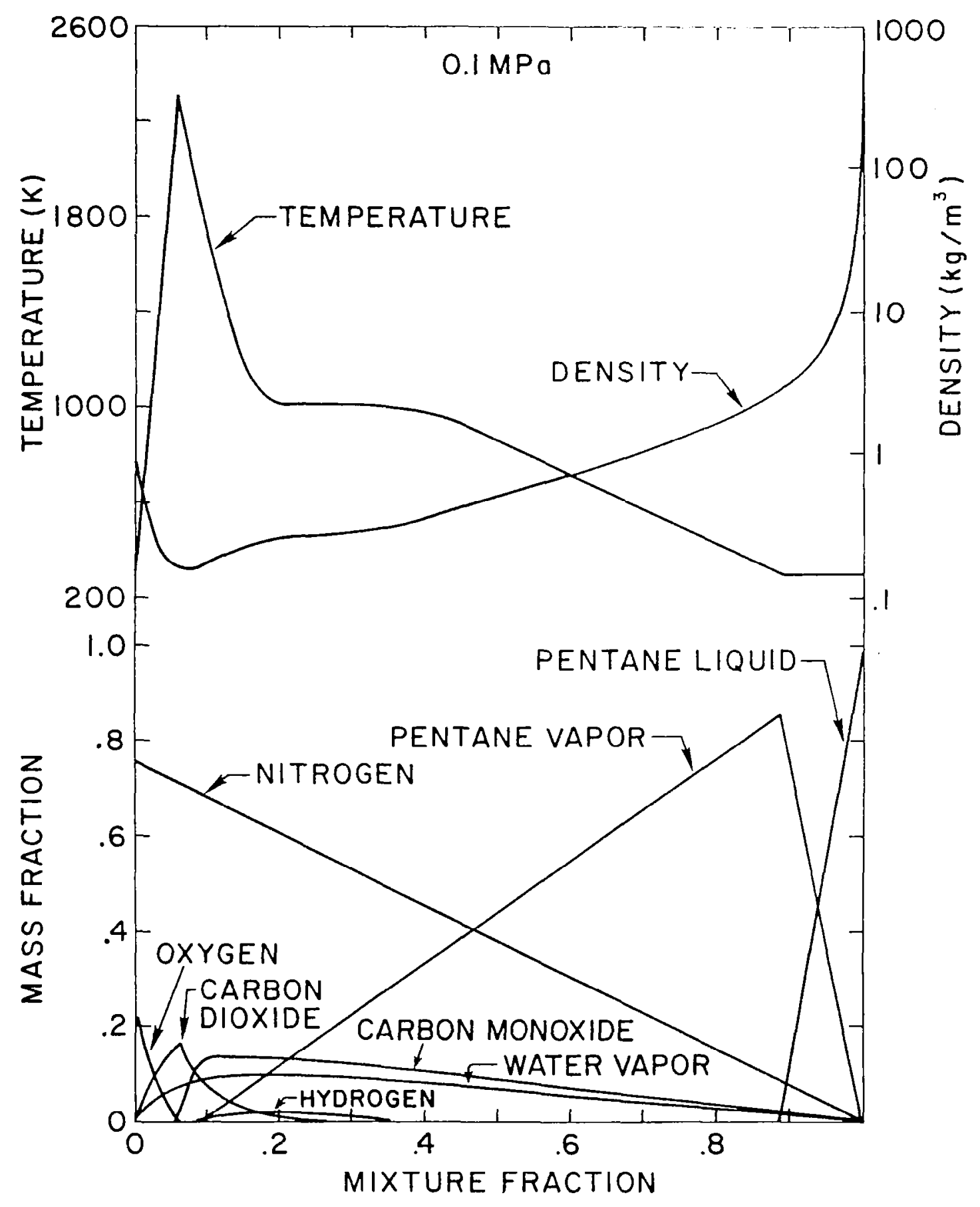

Figure 6. Equation of state for a combusting n-pentane spray in air at atmospheric pressure. 


\section{Table 3}

Summary of Pardneters Used in the Redlich-Kwong Equation of State ${ }^{a}$

\begin{tabular}{lcccc}
\hline$\Omega_{\mathrm{ai}}$ & \multicolumn{3}{c}{0.4278} \\
$\Omega_{\mathrm{bi}}$ & \multicolumn{3}{c}{0.0867} \\
\hline $\mathrm{k}_{\mathrm{ij}}$ & $\mathrm{C}_{5} \mathrm{H}_{12}$ & $\mathrm{~N}_{2}$ & $\mathrm{CO}$ & $\mathrm{H}_{2} \mathrm{O}$ \\
\hline $\mathrm{C}_{5} \mathrm{H}_{12}$ & 0 & 0.25 & 0 & 0.30 \\
$\mathrm{~N}_{2}$ & 0.25 & 0 & 0 & 0 \\
$\mathrm{CO}$ & 0 & 0 & 0 & 0 \\
$\mathrm{H}_{2} \mathrm{O}$ & 0.30 & 0 & 0 & 0 \\
$\cdots$
\end{tabular}

${ }^{a}$ Critical properties and acentric factors for each species where obtained from Reid, et al (24). 
By definition

$$
\sum x_{\dot{i}_{f}}=\sum x_{i_{g}}=1
$$

High pressure phase equilibrium implies that the fugacity of each species is the same in both phases, yielding four equations, as follows

$$
F_{i}\left(X_{j}, p, T\right)=F_{i_{f}}\left(X_{j_{f}}\left(X_{j_{f}}, p, T\right)\right.
$$

where the fugacity of each species depends on the composition in each phase. Finally, conservation of energy provides

$$
\mathrm{h}_{\mathrm{Ff}}+\nu_{\mathrm{O}}^{\prime} \mathrm{h}_{\mathrm{O}_{2}}+\nu_{\mathrm{N}_{2}}{ }_{2} \mathrm{~h}_{\mathrm{N}_{\infty}}=\mathrm{n}_{\mathrm{f}} \sum \mathrm{x}_{\mathrm{i}_{\mathrm{f}}}{ }^{\mathrm{h}_{\mathrm{i}}}+\mathrm{n}_{\mathrm{g}} \sum \mathrm{X}_{\mathrm{i}_{\mathrm{g}}} \mathrm{h}_{\mathrm{i}}
$$

The Redlich-Kwong equation of state provides enthalpy deviations from the ideal gas condition, at each temperature, so that compressibility effects and phase could be considered in the evaluation of the $h_{i}$ for the products. Compressibility was also considered when the LHS of Eq. (9) was evaluated. The Redlich-Kwong equation of state also provides the specific volumes for both phases, which can be used to compute the density of the mixture, given $n_{f}$ and $n_{g}$.

With the mixture fraction and pressure prescribed, Eqs. (6) (9) provide eleven equations to solve for the eleven unknowns. The solution was carried out using a computer program developed in earlier work $(22,24)$. When no liquid is present, the composition is given immediately by Eq. (1). The equation of state then provides the enthalpy deviations and mixture specific volume for use in the remainder of the computation.

Figure 7 is an illustration of a high pressure equation of state constructed in this manner. The operating condition involves liquid $n$-pentane, buming in air, at a pressure of $6 \mathrm{MPa}$. The reactants all have initial temperatures of $300 \mathrm{~K}$. The low mixture fraction region is similar to Figs. 5 and 6 , having a temperature maximum and a density minimum near the stoichiometric mixture ratio. Liquid is present for mixture fractions greater than 0.8 , but the behavior of the two-phase mixture differs from that at low pressures, illustrated in Fig. 6. At low pressures, the mass fraction of gaseous nitrogen, for example, varies in a linear fashion with mixture fraction. This is not the case at high pressures, since appreciable quantities of nitrogen are dissolved in the liquid phase. The combustion product gases behave in a similar manner. Due to the accumulation of dissolved gases, the liquid fraction decreases more slowly, with decreasing mixture fraction, than at low pressures. 


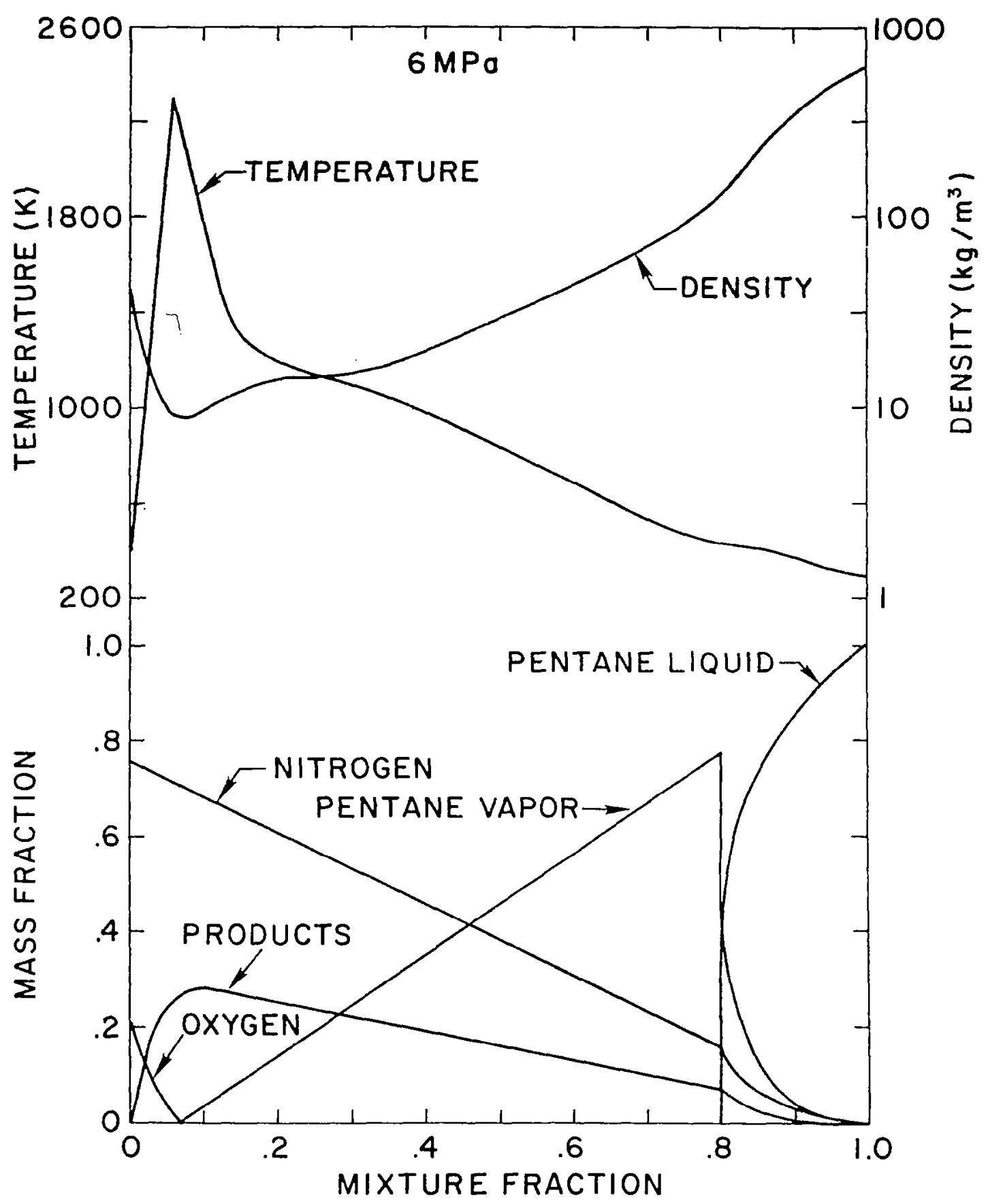

Figure 7. Equation of state for a combusting n-pentane spray in air at $6 \mathrm{MPa}$. 
4.3 Governing Equations. Variable density effects for turbulent flow are treated by Reynolds averaging, following the work of Lockwood and coworkers $(11,18)$. The Boussinesq approximation is used to represent velocity-density correlations, although a number of terms introduced by density fluctuations must be ignored, for lack of better information $(9,10)$.

Employing the assumptions discussed earlier, the equations of motion become:

$$
\frac{\partial \bar{p} \bar{u}}{\partial x}+\frac{1}{r} \frac{\partial}{\partial r}\left(r \bar{\rho} \bar{v}^{o}\right)=0
$$

$D(\vec{u})=a\left(\bar{\rho}_{\infty}-\bar{\rho}\right)$

$D(\bar{f})=0$

$D(k)=\mu_{t}\left(\frac{\partial \bar{u}}{\partial r}\right)^{2}-\bar{p} \varepsilon$

$D(\varepsilon)=C_{\varepsilon 1} \mu_{t} \frac{\varepsilon}{k}\left(\frac{\partial \bar{u}}{\partial r}\right)^{2}-C_{\varepsilon 2} \bar{\rho} \frac{\varepsilon^{2}}{k}$

$D(g)=C_{g 1} \mu_{t}\left(\frac{\partial \bar{f}^{2}}{\partial r}\right)^{2}-C_{g 2} \bar{\rho} \frac{\varepsilon g}{k}$

where

$$
\bar{\rho} \bar{v}^{o}=\bar{\rho} \bar{v}+\overline{\rho^{\prime} v^{\prime}}
$$

and for

$$
\phi=\overline{\mathrm{u}}, \overline{\mathrm{f}}, \mathrm{k}, \varepsilon \text { or } \mathrm{g}
$$

$\mathrm{D}(\phi)=\bar{\rho} \overline{\mathrm{u}} \frac{\partial \phi}{\partial \mathrm{x}}+\bar{\rho} \overline{\mathrm{v}} \frac{\partial \phi}{\partial \mathrm{r}}-\frac{1}{\mathrm{r}} \frac{\partial}{\partial \mathrm{r}}\left(\mathrm{r} \frac{\mu_{\mathrm{t}}}{\sigma_{\phi}} \frac{\partial \phi}{\partial \mathrm{r}}\right)$ 
The turbulent viscosity is obtained from $\varepsilon$ and $k$ as follows:

$$
\mu_{t}=c_{\mu} \bar{\rho} k^{2} / \varepsilon
$$

The boundary conditions for Eqs. (11) - (19), in the region following the potential core of the jet are

$$
r=0, \frac{\partial \phi}{\partial r}=0 ; r \rightarrow \infty, \phi=0
$$

The initial conditions for the flow are

$$
\mathrm{x}=0, \mathrm{r}<\mathrm{d} / 2, \overline{\mathrm{u}}=\dot{\mathrm{M}}_{\mathrm{o}} / \dot{\mathrm{m}}_{\mathrm{o}}, \overline{\mathrm{f}}=1, \mathrm{~g}=0, \mathrm{k}=\mathrm{k}_{\mathrm{o}}, \varepsilon=\varepsilon_{\mathrm{o}}
$$

where the parameters $k$ and $\varepsilon$ are assumed to have the values appropriatc for fully devcloped flow in tubes.

The method of solution employs the GENMIX computer program, described by Patankar and Spalding (25). The computation begins in a shear layer, comprising one percent of the flow radius at the exit of the injector adjacent to the wall of the passage. All quantities are assumed to initially have a linear variation across the shear layer. The calculations proceed downstream, applying inner boundary conditions for the shear layer pertinent to flow conditions in the potential core (since the pressure is constant, conditions in the potential core are the same as at the exit of the injector). Once the shear layer reaches the centerline the inner boundary conditions are given by Eq. (20).

The parameters used in the calculation, step size, number of nodes, etc., were the same as in the earlier evaporating spray study. The various constants in the model were also unchanged from earlier work (9-11). Their values are summarized in Table 4.

4.4 Probability Density Function. The solution of Eqs. (11) (21) provides local values of $\overline{\mathrm{u}}, \overline{\mathrm{f}}, \mathrm{k}, \varepsilon, \mathrm{g}$. Other scalar quantities are determined from these variables, using the equation of state for the system (e.g., Figs. 5-7) and the probability density function $P(f)$ for $f$. Since the equation of state only depends upon $f$, mean values of scalars are given by

$$
\bar{\phi}=\int_{0}^{1} \phi(f) P(f) d f
$$


Table 4

Constants in the Turbulence Model

\begin{tabular}{llcl}
\hline Constant & Value & Constant & Value \\
\hline $\mathrm{C}_{\mu}$ & 0.09 & $\sigma_{\mathrm{f}}$ & 0.7 \\
$\mathrm{C}_{\varepsilon 1}$ & 1.44 & $\sigma_{\mathrm{k}}$ & 1.0 \\
$\mathrm{C}_{\varepsilon 2}=\mathrm{C}_{\mathrm{g} 2}$ & $1.89,1.84^{\mathrm{a}}$ & $\sigma_{\varepsilon}$ & 1.3 \\
$\mathrm{C}_{\mathrm{g} 1}$ & 2.8 & $\sigma_{\mathrm{g}}$ & 0.7 \\
\hline
\end{tabular}

${ }^{a}$ Constant and variable density flows, respectively. 
Following Lockwood and Naguib (11), a clipped Gaussian probability density function was assumed. This distribution contains two parameters which vary with position in the flow, the most probable value and the variance of the distribution. These parameters may be determined by noting that

$$
\bar{f}=\int_{0}^{1} f P(f) d f, g=\int_{0}^{1}(f-\bar{f})^{2} P(f) d f
$$

Both $\bar{f}$ and $g$ are known by integration of the conservation equations. Therefore, Eq. (23) provides two equations to solve for the most probable value and variance of the probability density function. Reference 10 provides further information on the methods used to solve Eq. (23) and to complete the integration of Eq. (22).

\section{RESULTS AND DISCUSSION}

5.1 Noncombusting Jets. In order to check experimental techniques, tests from earlier work $(9,10)$ were repeated. The flows considered were the constant density air jet and the variable density sulphur hexafluoride jet, both injected into stagnant air. The test conditions for these flows are summarized in Table 1 . These test conditions are somewhat different than Refs. 9 and 10 , due to changes in the test facility. The flows are sufficiently turbulent, however, so that calculations indicated no substantial variation in the normalized parameters reported here, due to the test condition changes.

Figure 8 is an illustration of the radial profile of mean axial velocity for various noncombusting flows $(9,10)$. The recent measurements for the isothermal single-phase jet (air jet) and variable density single-phase jet (sulphur hexafluoride jet) are shown as dark symbols. The calculations for the present test conditions gave results identical to the earlier calculations $(9,10)$. The present measurements are in good agreement with the earlier work and with theory.

Figure 9 is an illustration of the radial variation of mean mixture fraction from Refs. 9 and 10 , with the present measurements shown as dark symbols. Similar to Fig. 8, the new results are in good agreement with the earlier work and with theory.

The predictions of the LHF model for an evaporating spray (Freon 11 spray evaporating in air, injected with an $\mathrm{SMD}=29 \mu \mathrm{m}$ ) are also compared with measurements in Figs. 8 and 9 . When plotted this way, the predictions are in good agreement with measurements.

Figures 10 and 11 are illustrations of the axial variation of the mean axial velocity and mixture fraction at the centerline of the jet. A variety of single- and two-phase flows are considered. The 


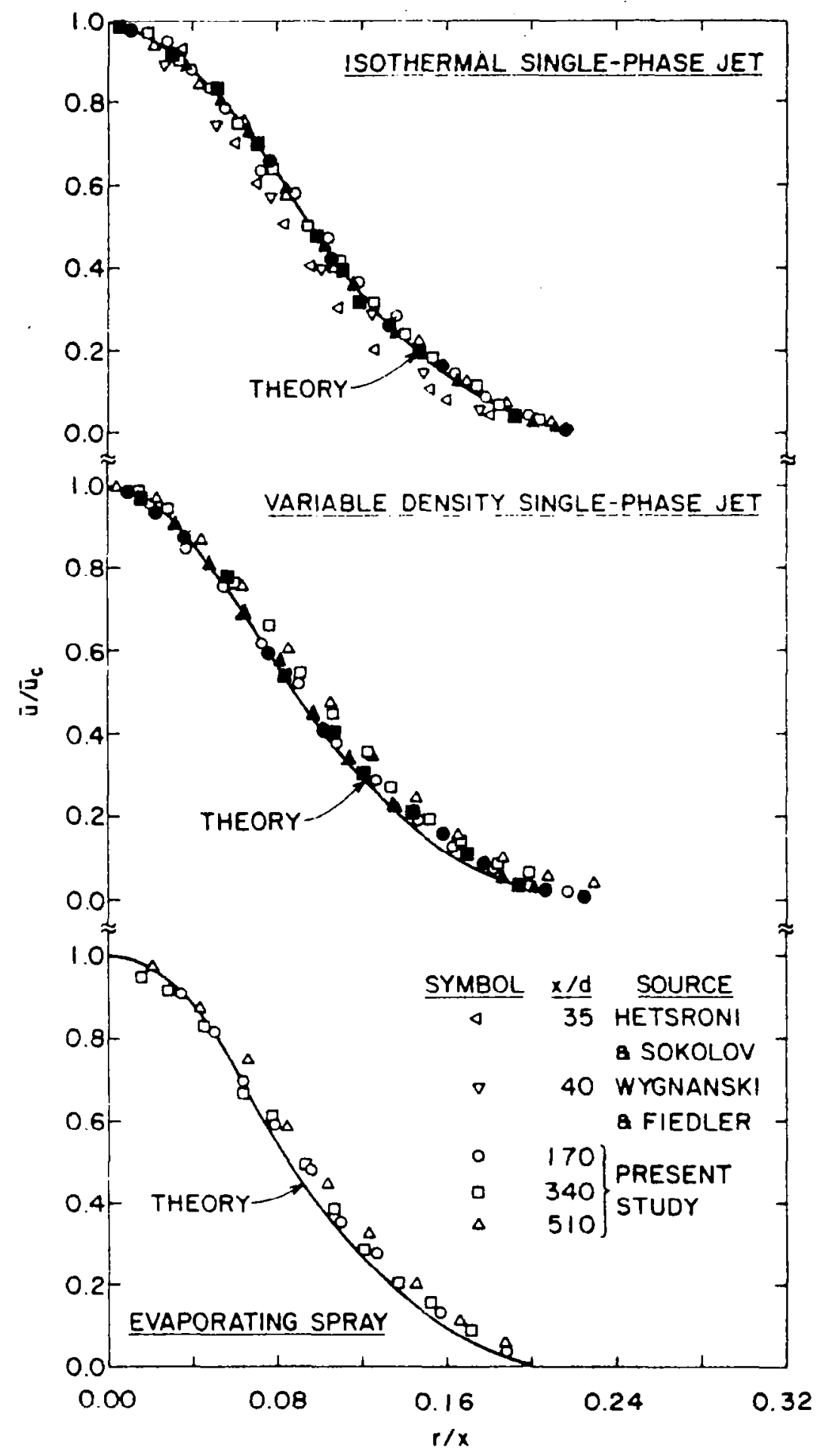

Figure 8 Radial Variation of Mean Axial Velocity 


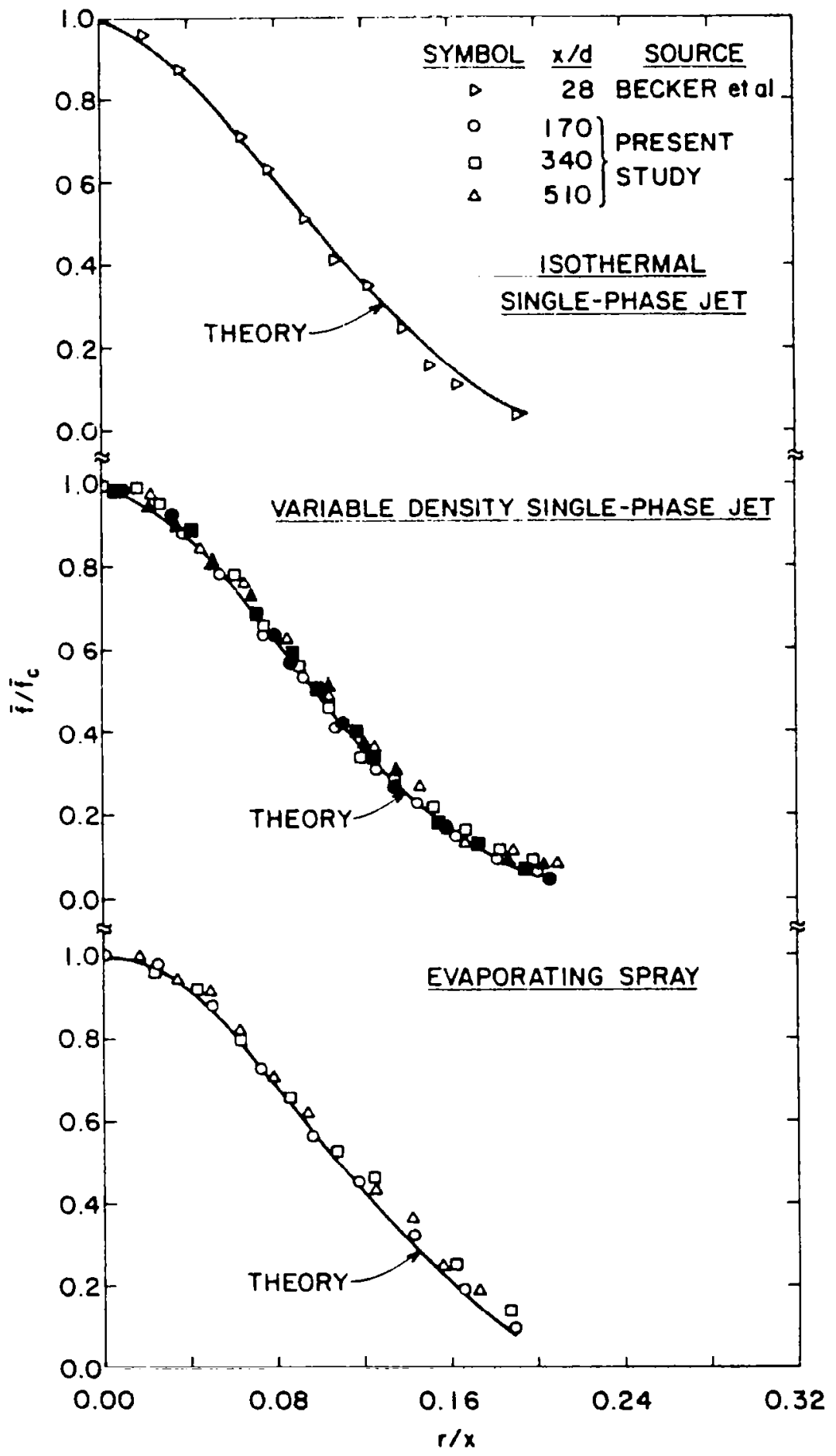

Figure 9 Radial Variation of Mean Mixture Fraction 


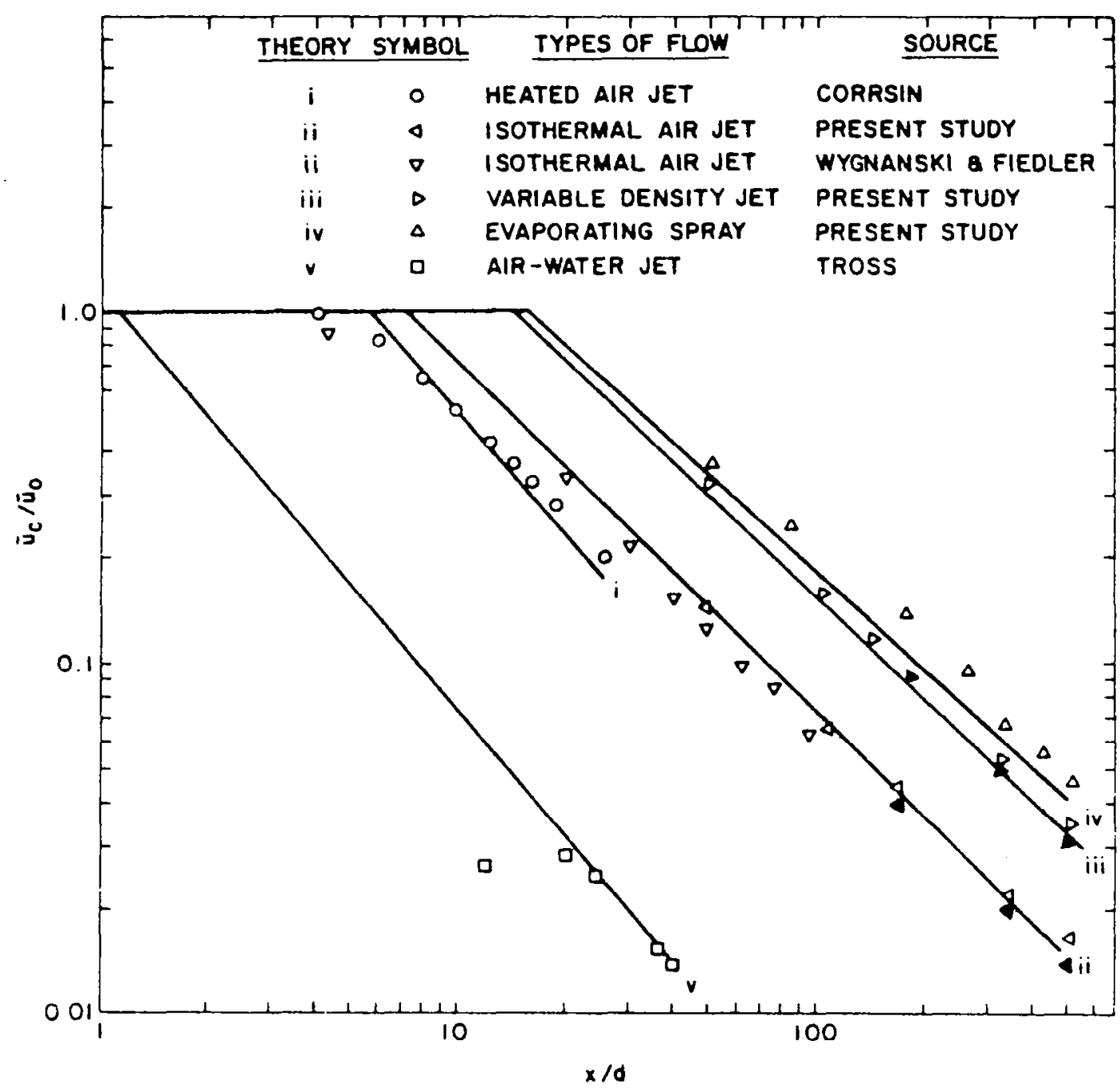

Figure 10. Axial Variation of the Centerline Velocity 


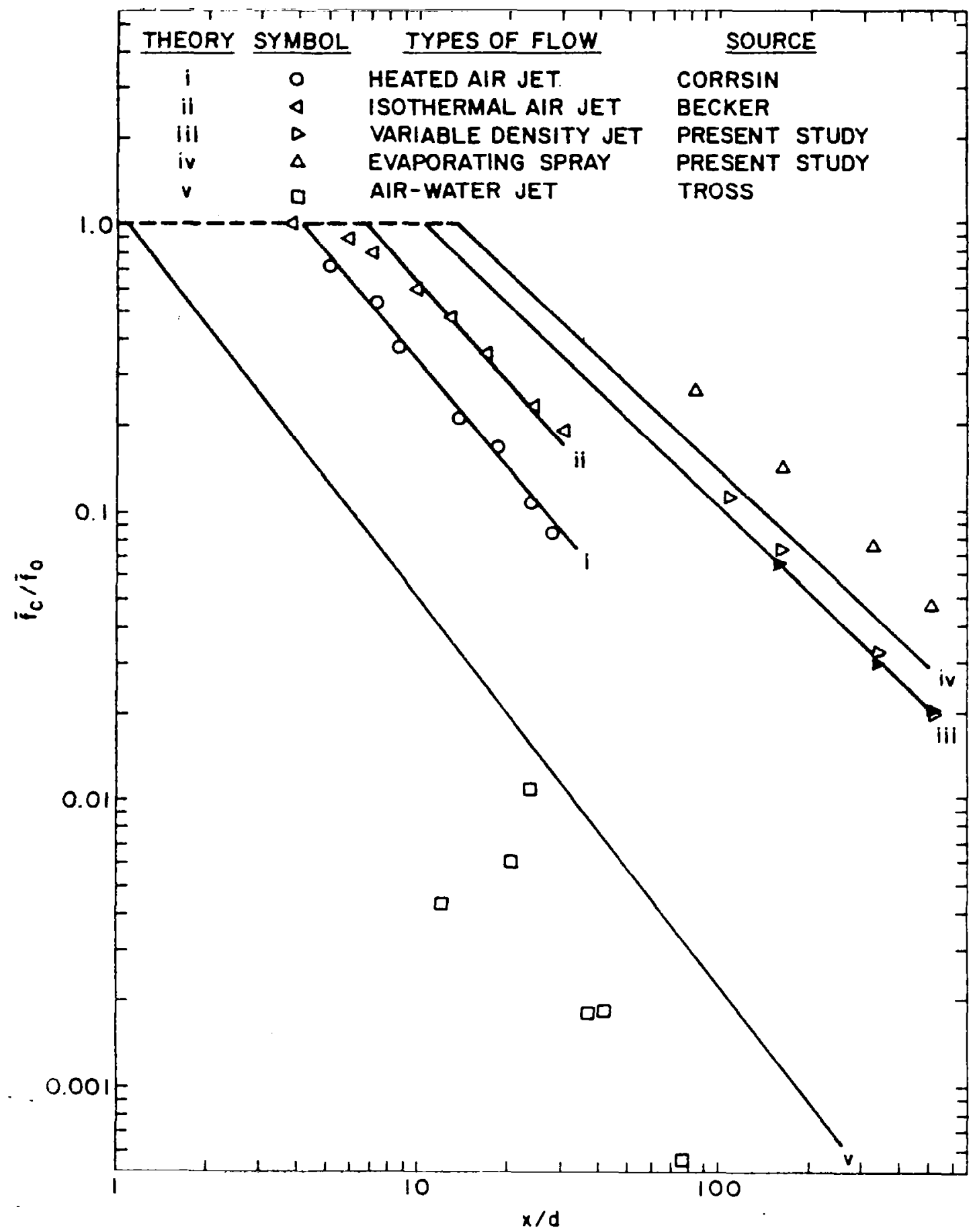

Figure 11. Axial Variation of the Centerline Mean Mixture Fraction 
present measurements, shown in dark symbols, are in good agreement with earlier measurements and theory. Notably in this case, the evaporating spray measurements are seen to lag the predictions $(9,10)$. This is evidence of an effect of finite interphase transport rates. Drop life history calculations, discussed in Refs. 9 and 10, demonstrate rather conclusively that this is the case.

5.2 Combusting Gas Jet. The test results for the combusting jet were obtained during the present study. The test conditions are summarized in Table 1. Profiles of mean axial velocity, mean temperature, turbulent kinetic energy and the Reynolds stress were moasured at values of $x / d=74.5,170,340$ and 510 within the combusting gas jet. The mean temperature was measured at additional locations along the centerline of the flow, in the range $x / d=21-600$. These measurements will be compared with the predictions of the single-phase turbulence model in the following.

Figure 12 is an illustration of the mean axial velocity profiles within the combusting gas jet. The velocity is normalized by the centerline velocity. Radial distances are represented by $r / x$, so that the prediction of flow width can be evaluated. Due to the effect of combustion, resulting in a large density variation in the flow field, the velocity profiles are not similar at the positions shown, in contrast to the results illustrated in Fig. 8 for noncombusting flows. In general, the predictions are in good agreement with the measurements.

Figure 13 is an illustration of radial profiles of mean temperature. The mean temperature is plotted directly as a function of $\mathrm{r} / \mathrm{x}$. The agreement between theory and experiment is quite good. The maximum temperature along the centerline of the jet is reached at a value of $x / d=200$. At shorter axial distances, the flame is located offaxis and has a maximum temperature somewhat below the maximum temperature at the centerline. All flame temperatures in the flow are lower than the adiabatic flame temperature for stoichiometric combustion of $2270 \mathrm{~K}$, c.f. Fig. 5. The lower values are due to turbulent unmixedness, which is represented in the calculations by the probability density function and $\mathrm{g}$. The results indicate that this aspect of the model is effective in terms of mean temperature predictions.

Figure 14 is an illustration of predicted and measured radial profiles of turbulent kinetic energy in the combusting jet. The theory is in good agreement with the measurements near the edge of the flow, but underestimates the turbulence kinetic energy near the centerline. Similar behavior was encountered for the noncombusting flows $(9,10)$. Although the value of $k$ is employed to estimate $\mu_{t}$, c.f. Eq. (19), the error in $k$ near the centerline does not have a large impact on the computation of the Reynolds stress, since the mean velocity gradient is small in this region. This point is illustrated in Fig. 15 where predicted and measured values of the 


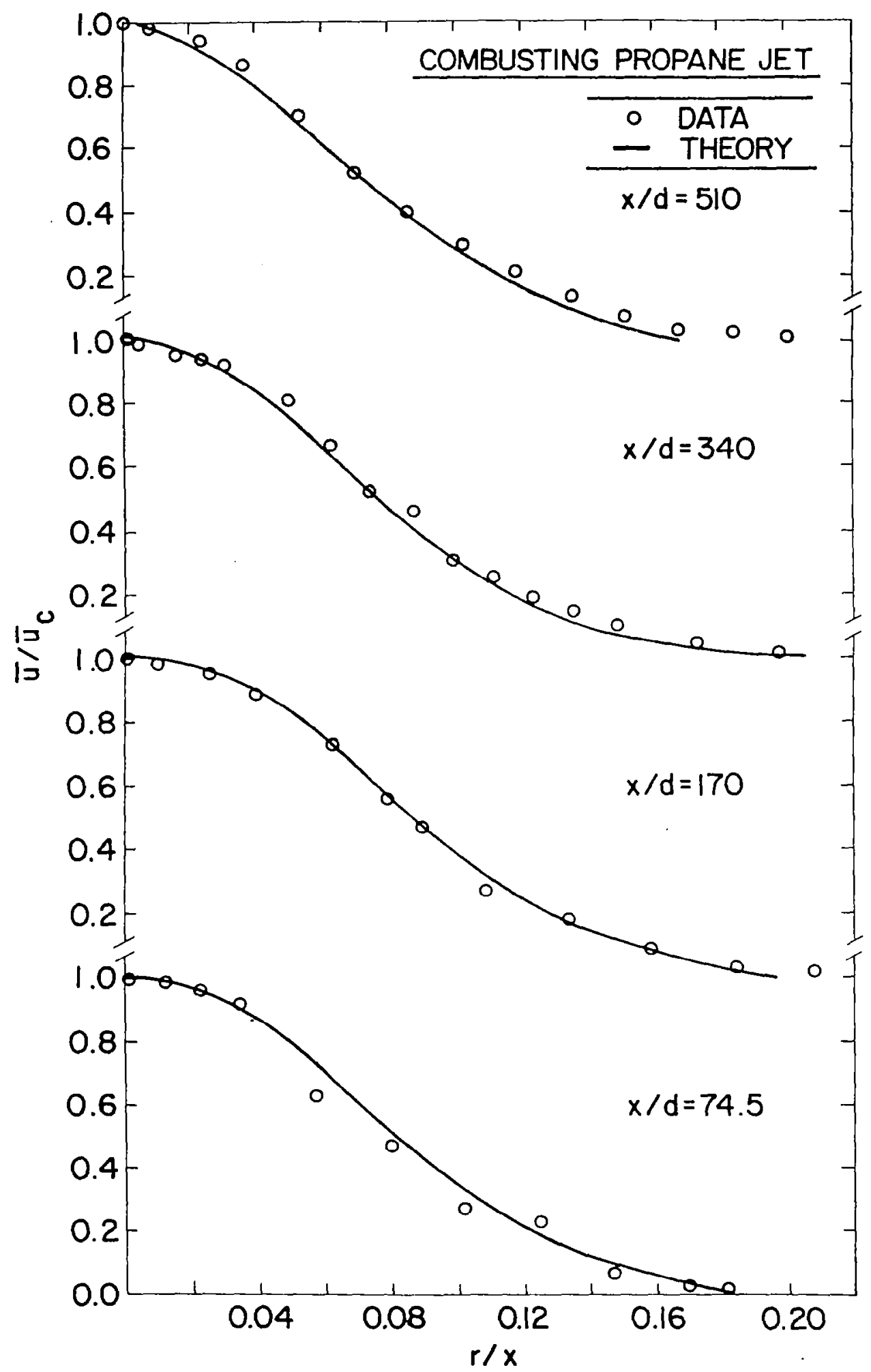

Figure 12. Radial variation of mean axial velocity in the combusting gas jet. 


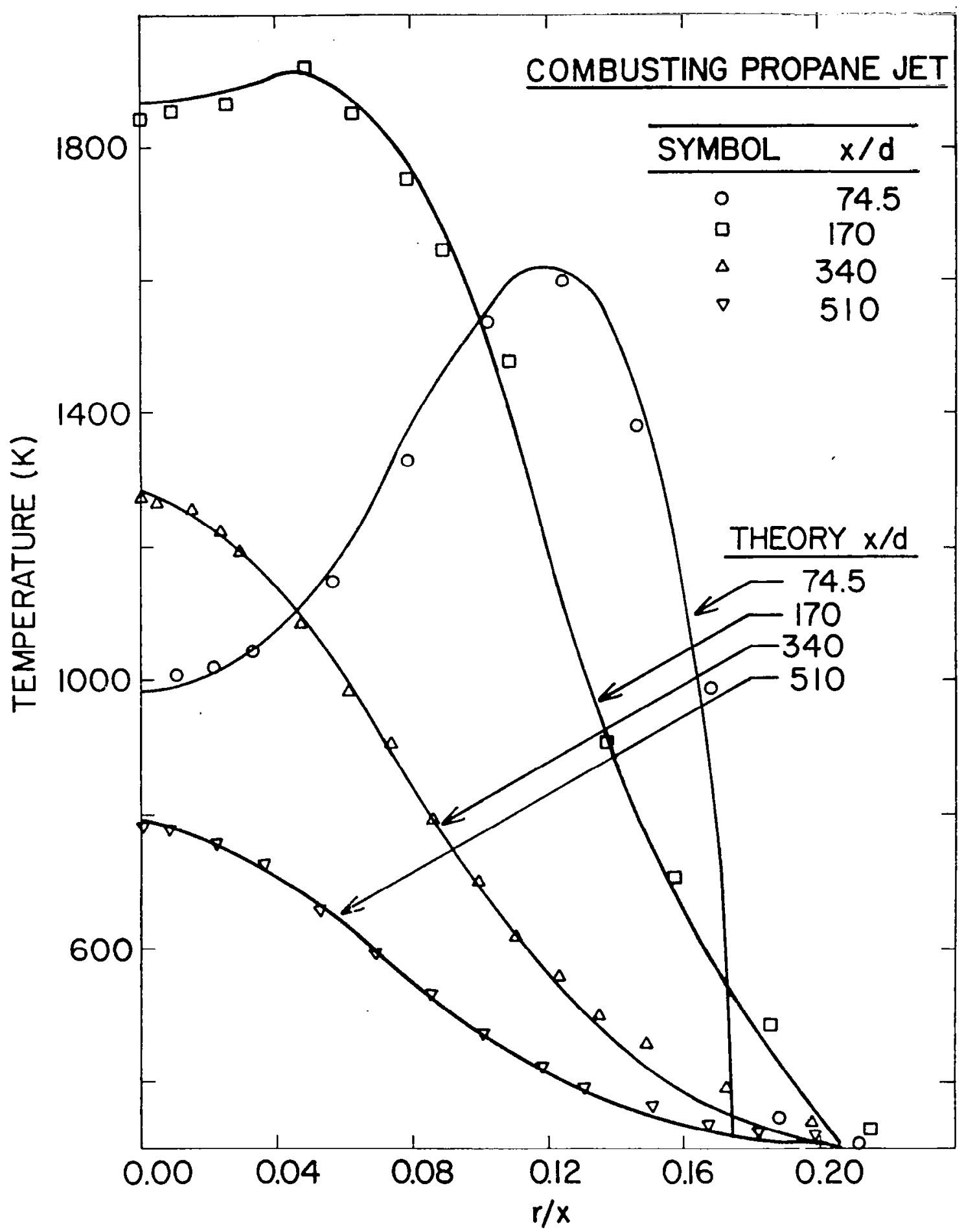

Figure 13. Radial variation of mean temperature in the combusting gas jet. 


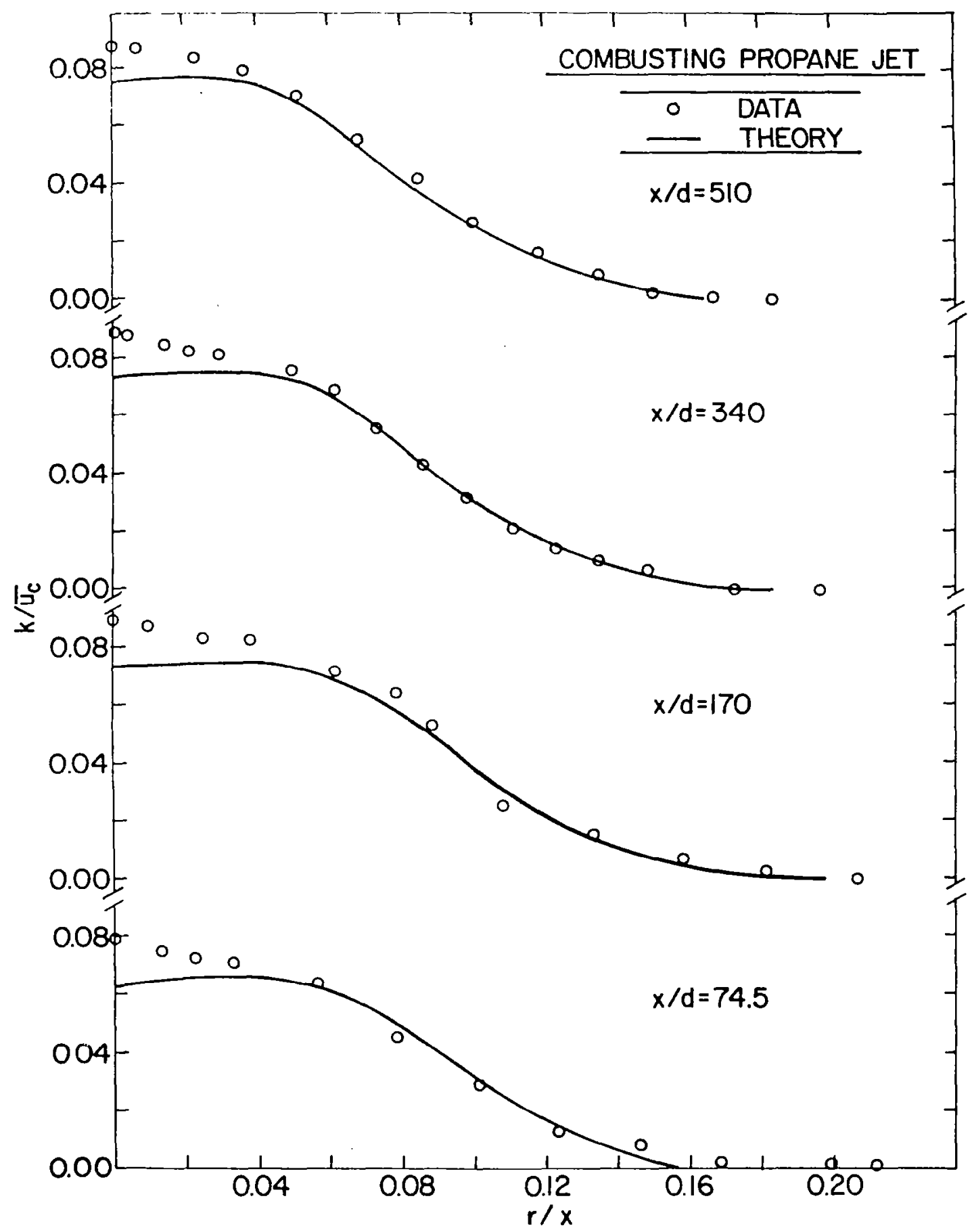

Figure 14. Radial variation of turbulence kinetic energy in the combusting gas jet.

33 


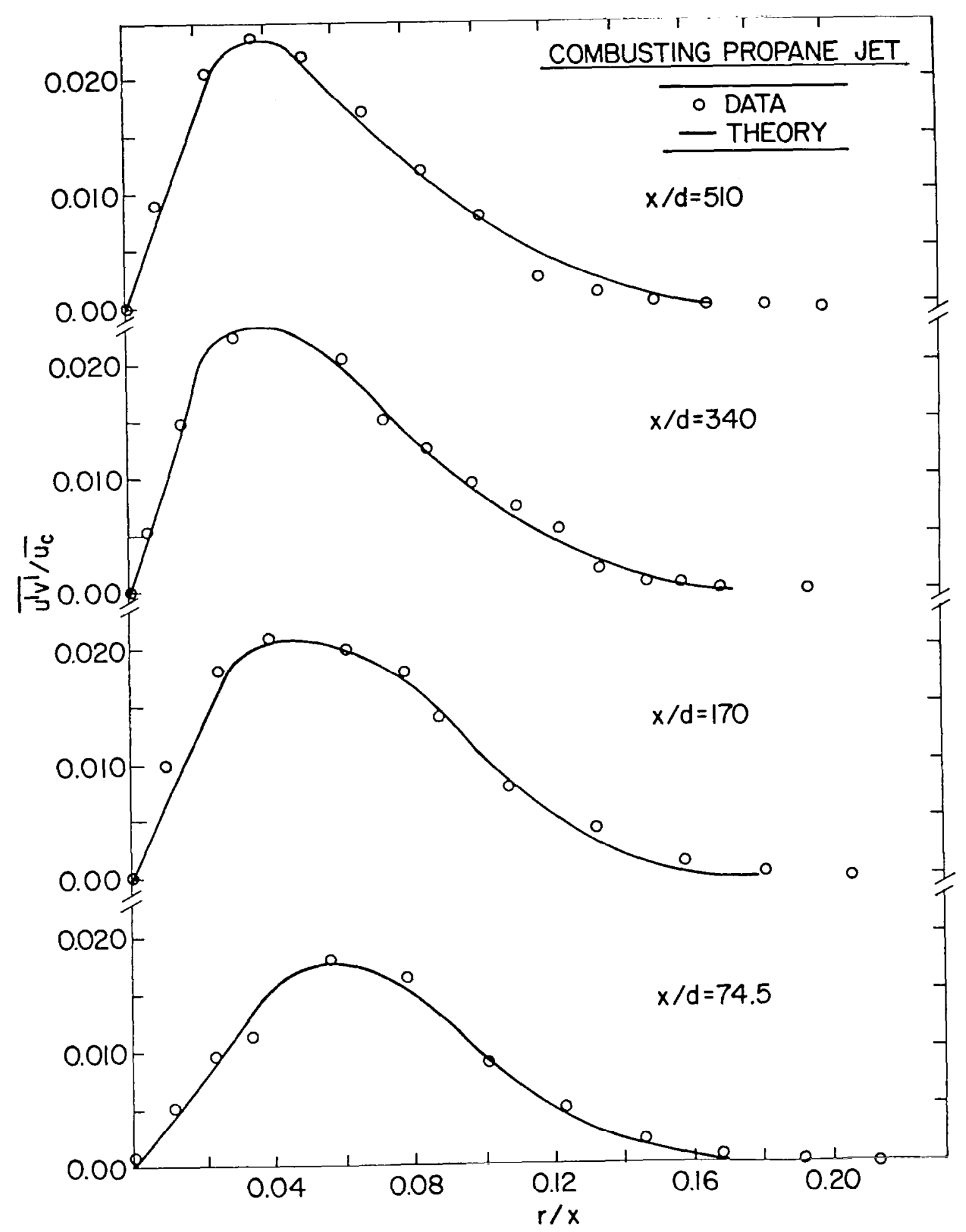

Figure 15. Radial variation of Reynolds stress in a combusting gas jet. 
Reynolds stress are compared. It is evident that the comparison between predictions and measurements is quite good.

Figure 16 is an illustration of mean axial velocity and mean temperature along the axis of the combusting jet, as a function of distance from the injector. Similar to the radial profiles of mean axial velocity and temperature, the agreement between predictions and measurements is excellent. Considering Figs. 12-16 as a whole, it is clear that the model provides a good description of the combusting jet. This general approach has also been successful in treating a variety of other single-phase combustion processes (18).

\subsection{Combusting Sprays.}

5.3.1 Atmospheric Pressure Conditions. The test results obtained during this investigation will be cmployed for the first evaluation of the LHF model. The test conditions are summarized in Table 1. The predictions are compared with measurements of mean axial velocity and mean temperature.

Mean axial velocities and temperatures at the spray centerline are plotted as a function of distance from the injector, in Fig. 17. In contrast to the gas jet, Fig. 16, the results illustrated in Fig. 17 suggest that the flow is developing more slowly than predicted. Near the end of the potential core, measured velocities are higher than predicted. The maximum temperature position is predicted to occur at $\mathrm{x} / \mathrm{d} \simeq 215$, while the measured position is roughly 275 , about 30 percent farther from the injector. Good agreement between predictions and measurements is only achieved at values of $x / d$ greater than 350 .

This behavior is an indication of an effect of finite rate processes between the phases. Based on the results of Refs. 9 and 10, for evaporating sprays, a discrepancy of this type is to be expected. The spray characteristics are similar in both cases, the injectors are the same, and drop life history calculations for the evaporating spray clearly demonstrated significant finite rate process effects in the region just downstream of the potential corc. Similar calculations are needed for the test results shown in Fig. 17, in order to firmly establish slip and loss of thermodynamic equilibrium between the phases as the reason for the differences between predictions and measurements.

Figure 18 is an illustration of the radial profiles of mean axial velocity in the combusting spray. The velocity is normalized by the centerline velocity, with radial distance given by $r / x$, in order to indicate the width of the flow. When plotted in this manner, the agreement between predictions and measurements is quite good. It should be recalled, however, that the centerline velocities, themselves, are not predicted very accurately for $\mathrm{x} / \mathrm{d}<350$, c.f. Fig. 17. Thus, the LHF theory is only providing a reasonable estimate of the width of the flow. This general behavior is similar to the findings for an evaporating spray $(8,10)$. 


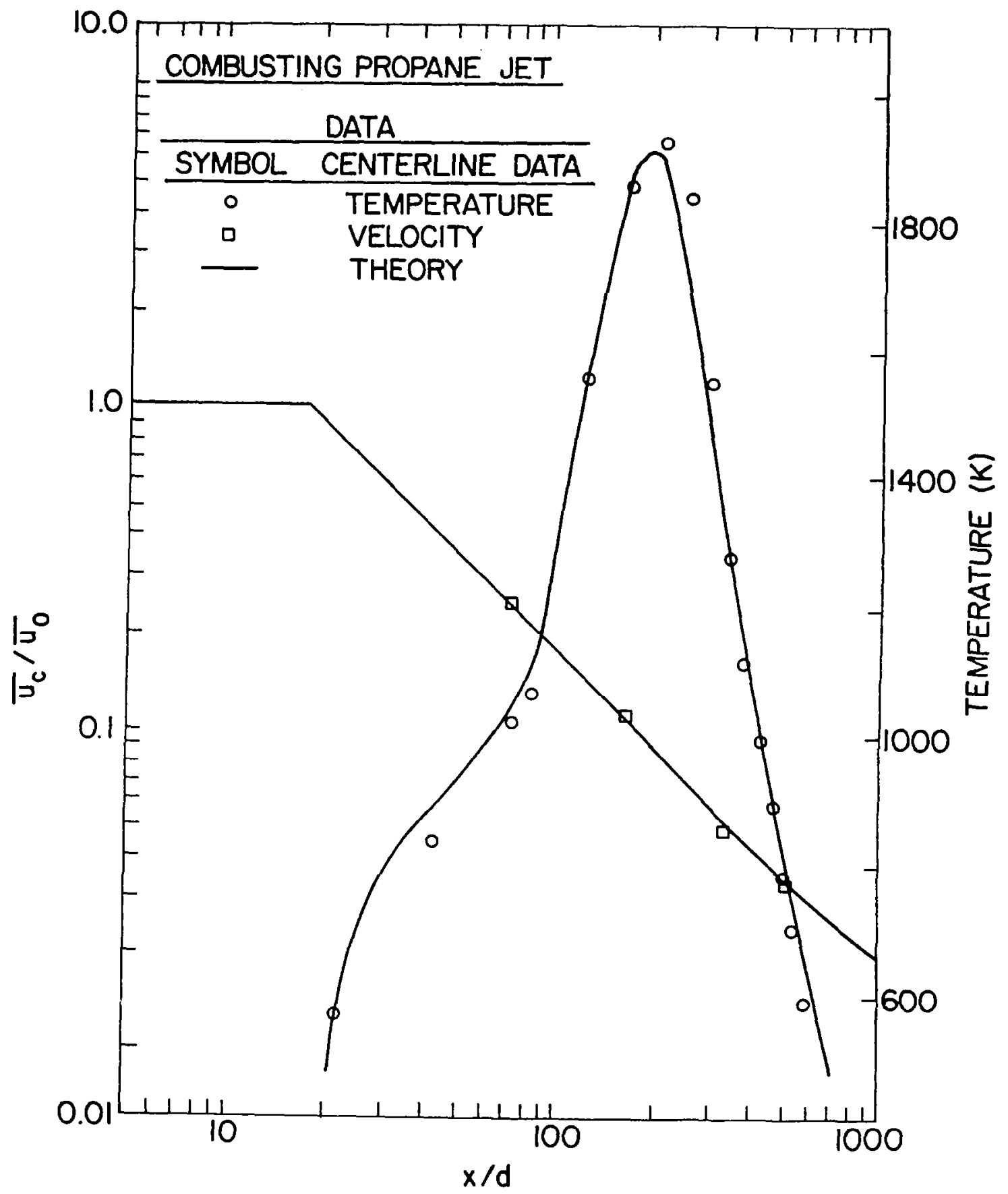

Figure 16. Theoretical and experimental mean velocity and temperature variation along the centerline of a combusting gas jet at atmospheric pressure. 


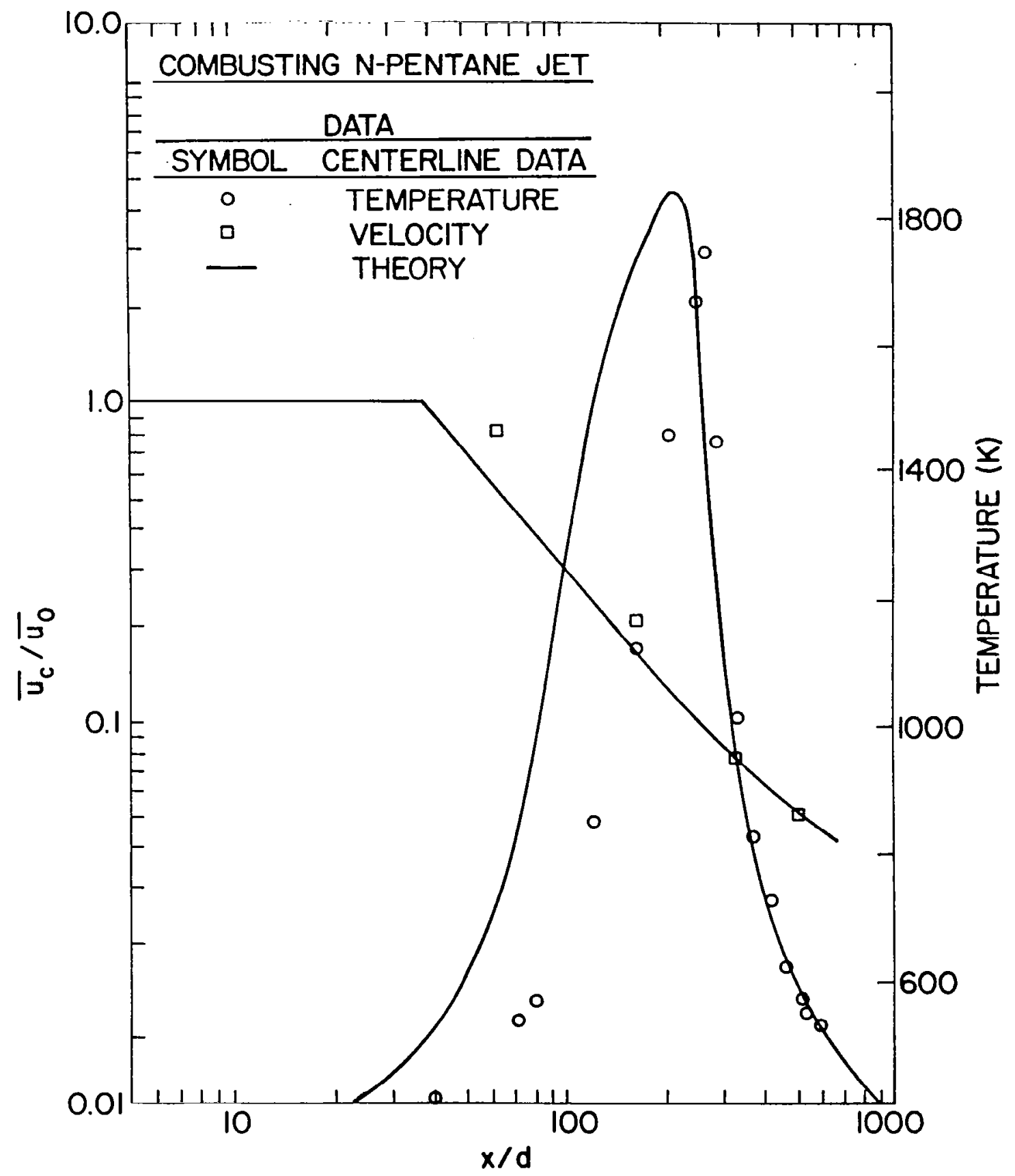

Figure 17. Theoretical and experimental mean velocity and temperature variation along the centerline of a combusting spray at atmospheric pressure. 


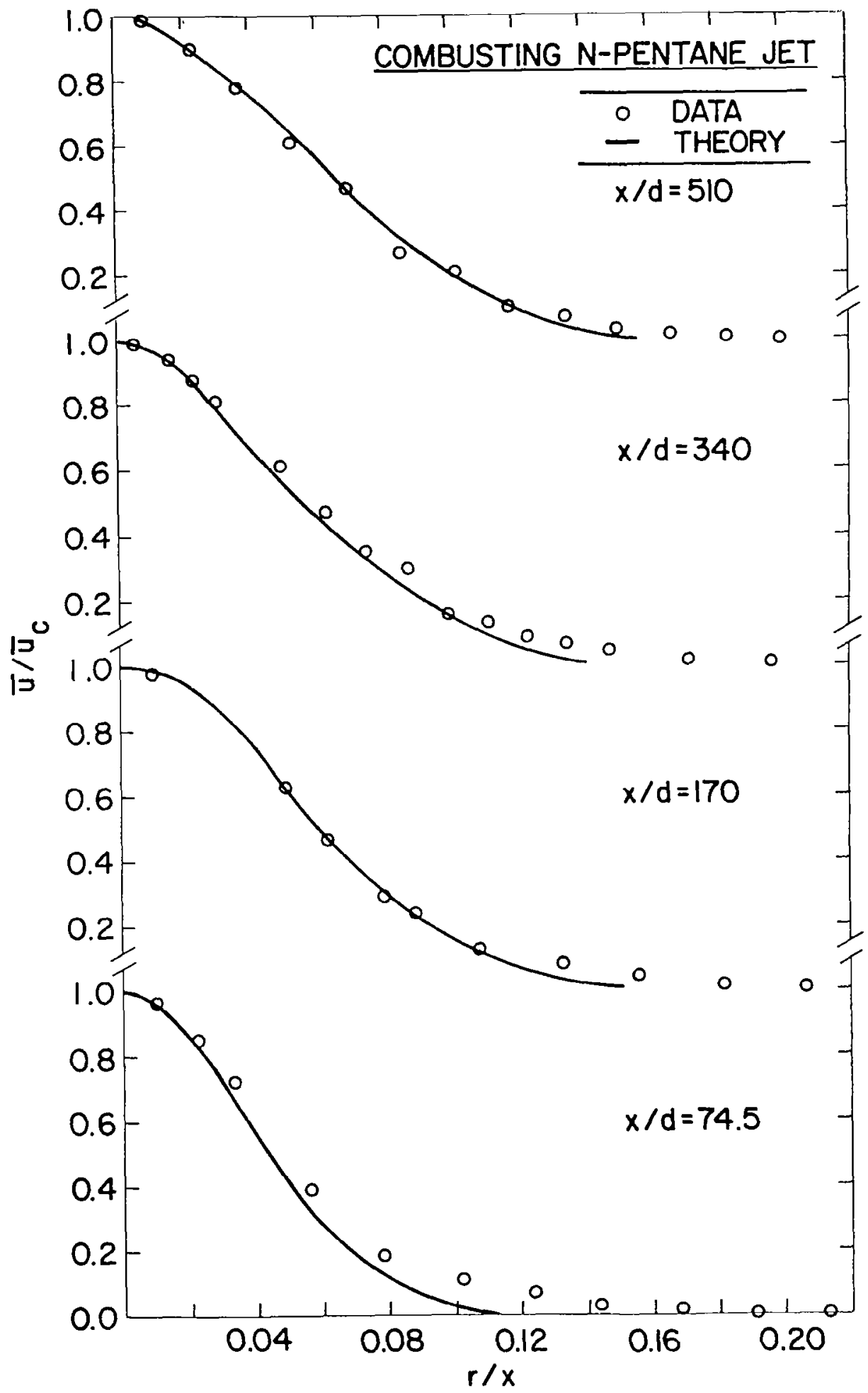

Figure 18. Radial variation of mean axial velocity in the combusting spray.

38 
Figure 19 is an illustration of radial profiles of mean temperature. The predictions of flow widths are reasonably accurate. The complete profile is predicted quite well for $\mathrm{x} / \mathrm{d}>340$. However, large discrepancies are observed between predictions and measurements near to the injector, since the theory overestimates the rate of development of the flow.

Some measurements of turbulence quantities were also completed for the combusting spray. Predicted and measured values of $k / \bar{u}^{2}$ and $\overline{u^{\prime} v^{\prime}} / \bar{u}_{c}^{2}$ were in reasonably good agreement, similar to observations for an evaporating spray. It appears that the theory adequately treats gas phase transport and combustion phenomena. The major problem is that the liquid phase does not exchange momentum and mass rapidly enough with the gas phase in order to satisfy the requirements of the LHF model. A spray having smaller drop sizes than the conditions employed to obtain the results illustrated in Figs. 17-19 would be required for quantitative accuracy with the LHF model. The estimation made for an cvaporating spray, using the same injector at atmospheric pressure, involved a spray SMD less than $10 \mu \mathrm{m}$ for quantitative accuracy with the LHF model $(9,10)$. A similar size range might be required for the present combusting spray, although drop-life-history calculations are required to firmly establish this.

\subsubsection{High Pressure Conditions. The test results for the} high pressure combusting spray were obtained from Ref. 8. The test conditions are summarized in Table 2. In this case, the only measurements available for comparison with theory are spray boundaries. The spray boundaries were measured from shadowgraphs.

Figure 20 is a comparison of predicted and measured spray boundaries at 3,6 and $9 \mathrm{MPa}$. The radial position is normalized with the injector radius, the axial position is normalized with the injector diameter. The predictions are in good agreement with the measurements at $3 \mathrm{MPa}$. Both thcory and experiment also suggest that the extent of the spray boundary is reduced as the pressure is increased. However, the theory overestimates the effect of pressure on reducing the length of the spray boundary. Predicted and measured spray lengths are summarized in Table 5. The discrepancy between predictions and measurements is 10-20 percent at pressures of 6 and $9 \mathrm{MPa}$.

The injector and the injector pressure drop were unchanged as ambient pressure was varied for the results illustrated in Fig. 20. Conventional wisdom suggests that finite interphase transport effects should become less important as the pressure increases in this circumstance, as long as the length of the process under consideration remains the same $(1,2)$. The process length tends to decrease with increasing pressures, for the results illustrated in Fig. 20. This effect could result in poorer predictions, even though increasing pressures would tend to reduce slip, etc. Experimental difficulties could also contribute to the discrepancy. At high pressures, density gradients are quite large, particularly toward the rich side of the flame. This could influence the appearance of the shadowgraphs, resulting in an overestimation 


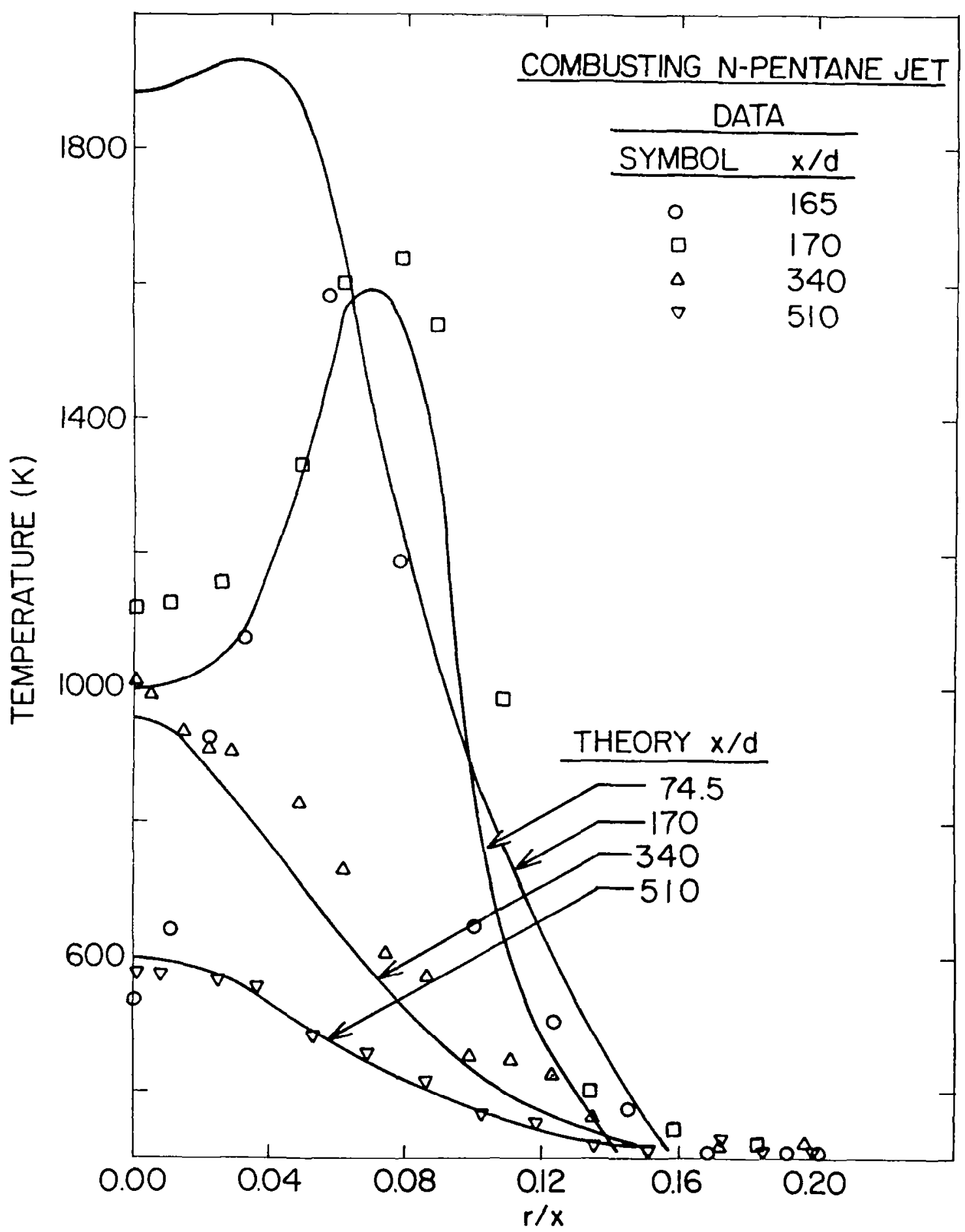

Figure 19. Radial variation of mean temperature in the combusting spray. 


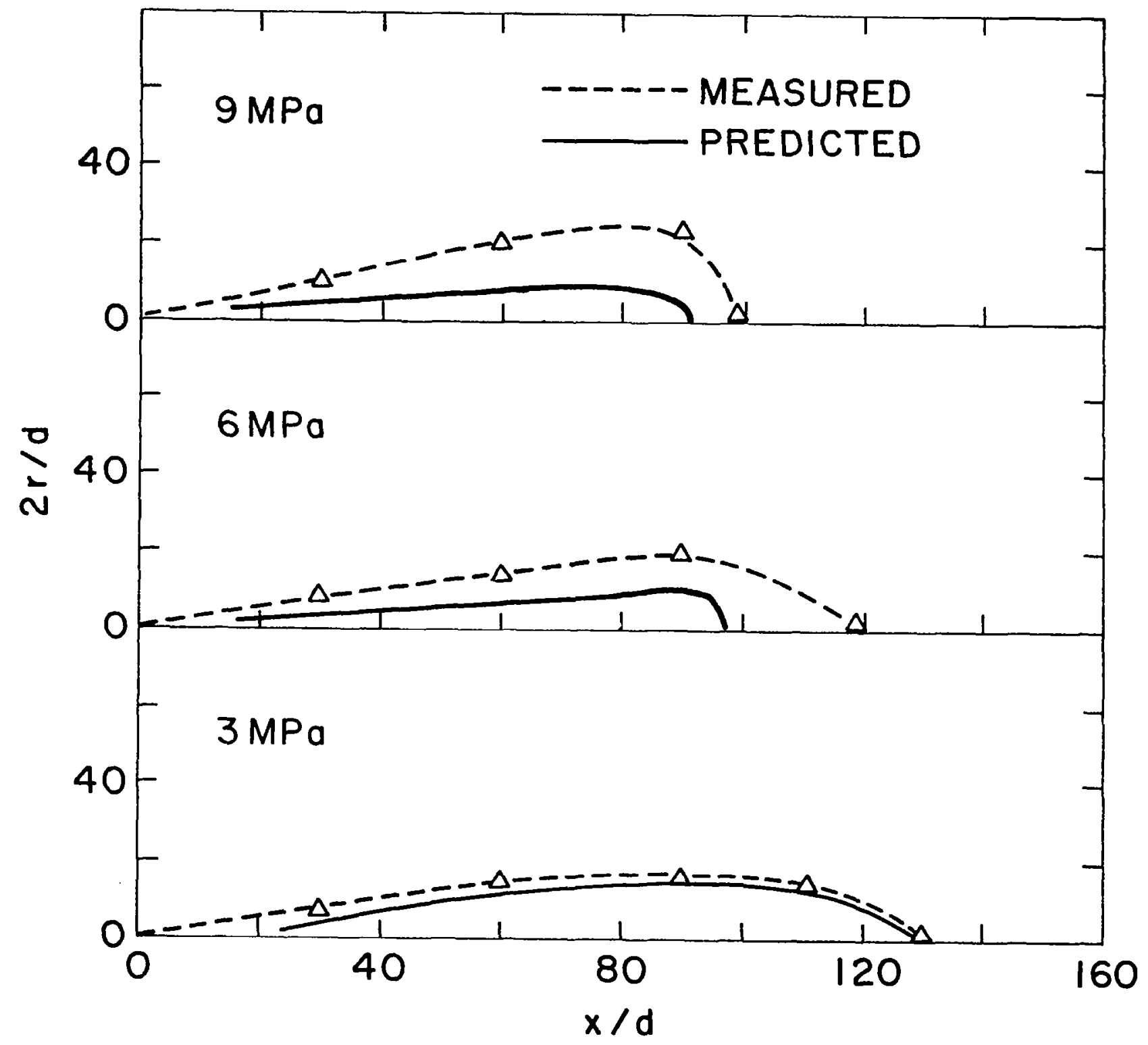

Figure 20. Theoretical and experimental spray boundaries at high pressures. 
$\underline{\text { Table } 5}$

Predicted and Measured Spray Penetration Lengths at High Pressures ${ }^{a}$

\begin{tabular}{cccc}
\hline $\begin{array}{c}\text { Pressure } \\
(\mathrm{MPa})\end{array}$ & $\frac{\text { Spray Length/Injector Diameter }}{\text { Measured }}$ & $\begin{array}{r}\text { Percent } \\
\text { Error }\end{array}$ \\
\hline 3 & 132 & 130 & 2 \\
6 & 119 & 96 & 19 \\
9 & 100 & 90 & 10 \\
\hline
\end{tabular}

$\mathrm{a}_{\text {Test }}$ conditions appear in Table 2

${ }^{\mathrm{b}}$ (Measured Value-Predicted Value)/Measured Value x 100 
of the extent of the spray. Further theoretical and experimental efforts will be required to fully evaluate the LHF model at high pressures. In particular, completion of drop life histories are needed to determine effects of slip in this flow.

Figure 21 is an illustration of the predicted variation of mean quantities along the centerline of the combusting spray, for a pressure of $3 \mathrm{MPa}$. The velocity and temperature profiles are qualitatively similar to the results obtained for the spray burning at atmospheric pressure, c.f. Fig. 17. The concentration of liquid fuel decreases monatonically with increasing distance from the injector. The concentration of fuel vapor reaches a maximum near the position where the liquid disappears and then decreases again as the flame is approached. The concentration of oxygen is small near the end of the potential core, and increases monotonically with increasing distance from the injector. Typical of turbulent diffusion flames, the fuel vapor and oxidant profiles overlap to a considerable degree.

Figure 22 is an illustration of the predicted radial variation of mean quantities in a combusting spray at $3 \mathrm{MPa}$. Three axial positions are shown, one before the point where the flame reaches the centerline, one near the maximum temperature position at the centerline and one in the post flame region. In the regions where fuel is present, the liquid fuel disappears first with increasing radial distance. The concentration of fuel vapor reaches a maximum at the point where the liquid disappears. Finally, the concentrations of fuel vapor and oxygen overlap in the flame.

\section{CONCLUSIONS}

A theoretical model for spray combustion was developed. The major elements of the theory are a $k-\varepsilon-g$ turbulence model with two-phase effects treated by the locally homogeneous flow (LHF) approximation. The empirical constants in the turbulence model were established using measurements in noncombusting flows. Combustion characteristics are handled using an equation of state, which relates physical properties to the instantaneous value of the mixture fraction, in conjunction with a probability density function for the mixture fraction. The statistical parameters in the probability density function are computed by the turbulence model at each point in the flow.

In an earlier study, the model was evaluated by comparison with measurements in a variety of noncombusting single- and two-phase flows $(9,10)$. The evaluation was extended to combusting flows during the present study. Measurements to evaluate the model were completed in this study in a combusting gas jet and combusting spray, at atmospheric pressure. Results from an earlier study on high pressure spray combustion (8) were also employed for model evaluation purposes. In all cases, combustion occurred in stagnant air.

The conclusions of the study are as follows: 


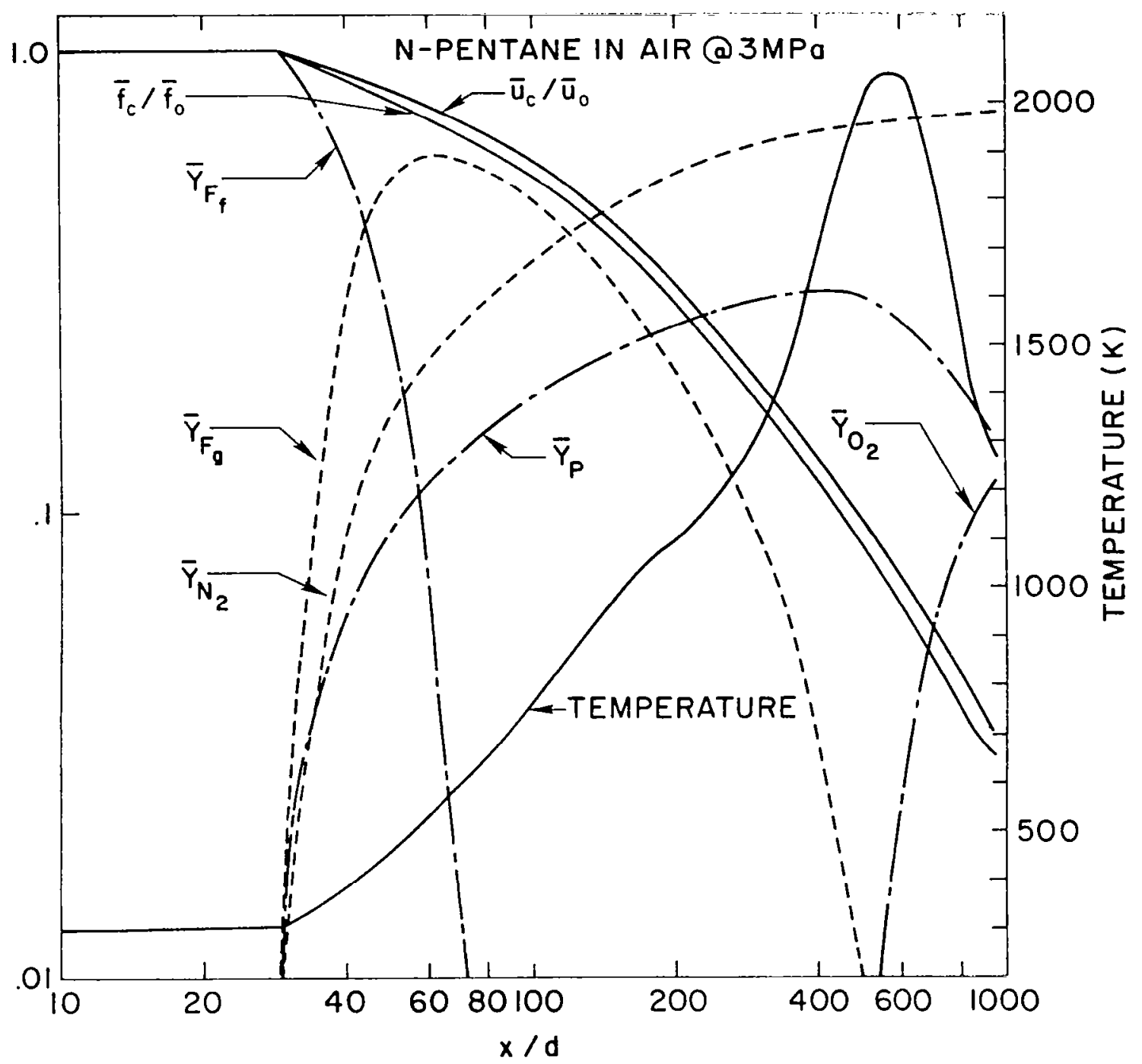

Figure 21. Predicted variation of mean quantities along the centerline of a combusting $\mathrm{n}$-pentane spray at $3 \mathrm{MPa}$. 


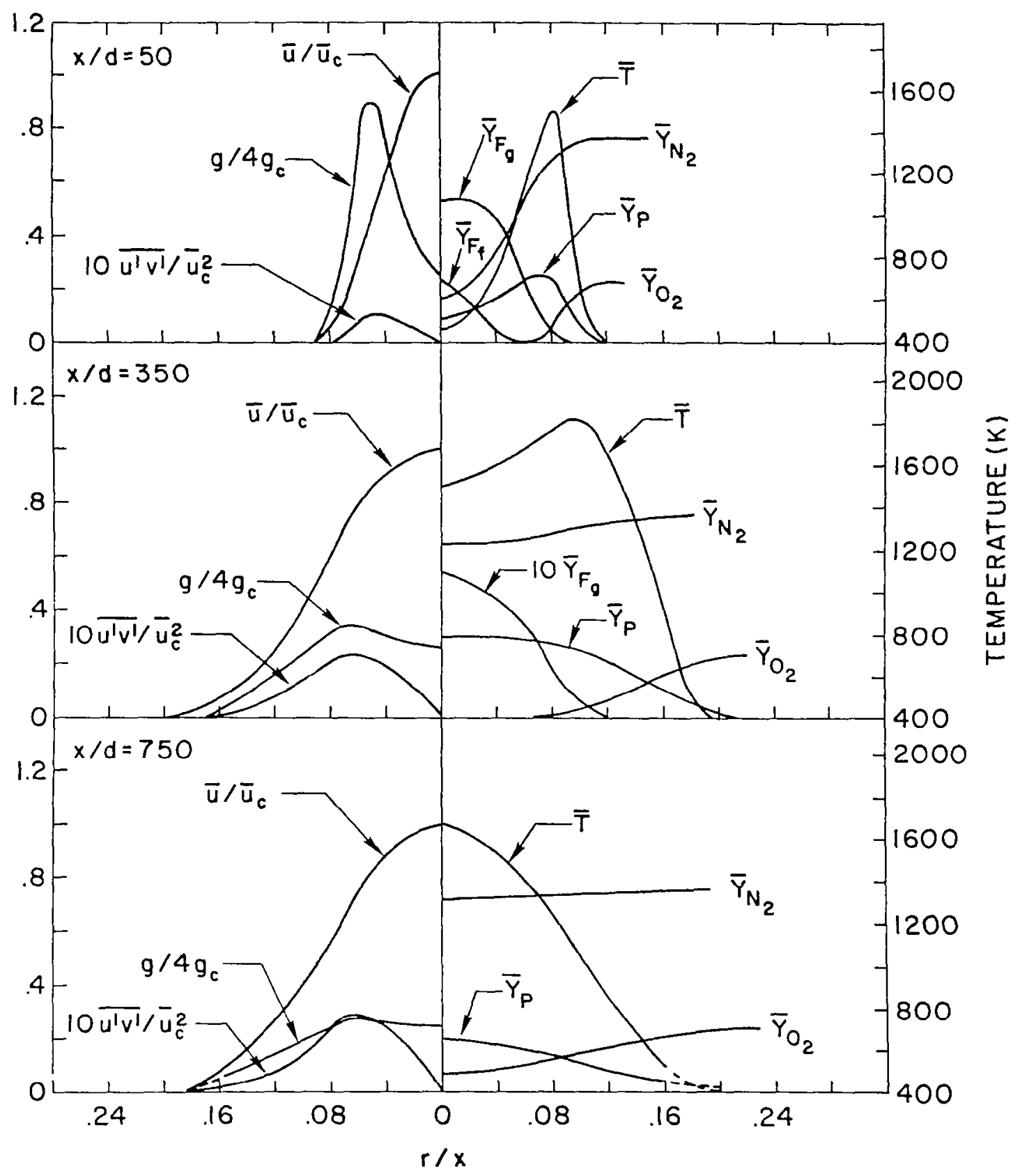

Figure 22. Predicted radial variation of mean quantities at various positions in a combusting $n$-pentane spray at $3 \mathrm{MPa}$. 
1. The comparison between predicted and measured mean and turbulent quantities in a combusting gas jet was excellent. The model is clearly capable of treating gaseous diffusion flames, confirming the findings of other workers employing models of this type $(18,21)$.

2. The model tends to overestimate the rate of development of combusting sprays, even for sprays having Sauter mean diameters of 28-35 $\mu \mathrm{m}$. This observation agrees with earlier results for evaporating sprays having similar injector conditions $(9,10)$. However, the model is qualitatively correct. Exrors in spray and flame lengths were on the order of 30 percent. Thus, the model provides a reasonable first estimate of the extent and character of a spray combustion process while requiring only a limited degree of empirical information on injector and turbulence characteristics.

3. Errors in the model are largely attributed to effects of finite interphase transport rates, i.e., the presence of slip and loss of thermodynamic equilibrium between the phases which invalidates the LHF approximation. These effects appear to be important in all practical sprays considered to date. Thus, one of the greatest values of the model is that it provides a lower bound for the size of an anticipated spray combustion process -- all real spray processes will require a larger volume due to finite interphase transport rates. With model results of this type available, the potential improvement to be realized by improved injection can be estimated prior to testing.

4. Aspects of the assessment of the model are still incomplete. Drop-life-history calculations are needed for the combusting sprays in order to provide a more convincing evaluation of the effect of interphase transport rates. The data for high pressure sprays was very limited and there is some question concerning its accuracy. Further measurements at high pressures are needed to evaluate the model more completely.

5. Improvements to the basic model would also be desirable. Major questions concern the applicability of Reynolds-averaging for variable density flows, the form of the probability density function for mixture fraction, and the impact of flammability limits and fuel decomposition (soot formation) on the construction of the equation of state. 


\section{REFERENCES}

1. G. M. Faeth, "Current Status of Droplet and Liquid Combustion," Prog. Energy Combust. Sci., Vol. 3, pp. 191-224, 1977.

2. G. M. Faeth, "Spray Combustion Models--A Review," AIAA Paper No. 79-0293, AIAA 17th Aerospace Sciences Meeting, New Orleans, January 1979 .

3. M. W. Thring and M. P. Newby, "Combustion Length of Enclosed Turbulent Jet Flames," Fourth Symposium (Internationa1) on Combustion, The Combustion Institute, Pittsburgh, pp. 786-796, 1953 .

4. J. A. Newman and T. A. Brzustowski, "Behavior of a Liquid Jet Near the Thermodynamic Critical Region," AIAA J, Vol. 9, pp. 1595-1602, 1971 .

5. Y. Onuma and M. Ogasawara, "Studies on the Structure of a Spray Combustion Flame," Fifteenth Symposium (International) on Combustion, The Combustion Institute, Pittsburgh, pp. 453-465, 1975.

6. H. Hiroyasu and T. Kadota, "Models for Combustion and Formation of Nitric Oxide and Soot in Direct Injection Diesel Engines," SAE Paper 760129, 1976.

7. E. E. Khalil and J. H. Whitelaw, "Aerodynamic and Thermodynamic Characteristics of Kerosene Spray Flames," Sixteenth Symposium (Internationa1) on Combustion, The Combustion Institute, Pittsburgh, pp. 569-576, 1976.

8. A. J. Shearer and G. M. Faeth, "Combustion of Liquid Sprays at High Pressures," NASA CR-135210, March 1977.

9. A. J. Shearer, H. Tamura and G. M. Faeth, "Evaluation of a Locally Homogeneous Flow Model of Spray Evaporation," J. Energy, in press. Also see AIAA Paper No. 78-1042, 1978, by the same authors.

10. A. J. Shearer and G. M. Faeth, "Evaluation of a Locally Homogeneous Model of Spray Evaporation," NASA CR-3198, 1979.

11. F. C. Lockwood and A. S. Naguib, "The Prediction of Fluctuations in the Properties of Free, Round-Jet, Turbulent, Diffusion Flames," Combustion and Flame, Vol. 24, pp. 109-124, 1975. 
12. G. Hetsroni and M. Sokolov, "Distribution of Mass, Velocity, and Intensity of Turbulence in a Two-Phase Turbulent Jet," Trans. ASME, J. App1. Mech., Vo1. 38, pp. 314-327, 1971.

13. I. Wygnanski and H. E. Fiedler, "Some Measurements in the SelfPreserving Jet," J. Fluid Mech., Vo1. 38, pp. 577-612, 1969.

14. H. A. Becker, H. C. Hottel and G. C. Williams, "The Nozzle-Fluid Concentration Field of the Round, Turbulent, Free Jet," J. Fluid Mech., Vol. 30, pp. 285-303, 1967.

15. S. Corrsin and M. S. Uberoi, "Further Experiments on the Flow and Heat Transfer in a Heated Turbulent Air Jet," NACA Rept. No. 998,1950 .

16. S. R. Tross, "Characteristics of a Submerged Two-Phase Turbulent Free Jet," M. S. Thesis, The Pennsylvania State University, University Park, Pennsylvania, 1974.

17. R. A. Muegle, "Macimum Stable Droplets in Dispersoids," AIChEJ, Vol. 6, pp. 3-8, 1960.

18. A. D. Gosman, F. C. Lockwood and S. A. Syed, "Prediction of a Horizontal Free Turbulent Diffusion Flame," Sixteenth Symposium (International) on Combustion, The Combustion Institute, Pittsburgh, pp. 1543-1555, 1976 .

19. S. Gordon and B. J. McBride, "Computer Program for Calculation of Complex Chemical Equilibrium Compositions, Rocket Performance, Incident and Reflected Shocks, and Chapman-Jouguet Detonations," NASA SP-273, 1971.

20. F. C. Lockwood, "The Modeling of Turbulent Premixed and Diffusion Combustion in the Computation of Engineering Flows," Combustion and Flame, Vo1. 29, pp. 111-122, 1977

21. R. W. Bilger, "Turbulent Jet Diffusion Flames," Prog. Energy Combust. Sci., Vol. 1, pp. 87-109, 1976.

22. R. S. Lazar and G. M. Faeth, "Bipropellant Droplet Combustion in the Vicinity of the Critical Point," Thirteenth Symposium (Internationa1) on Combustion, The Combustion Institute, Pittsburgh, pp. 743-753, 1971 .

23. J. M. Prausnitz and P. L. Cheuh, Computer Calculations for High Pressure Vapor-Liquid Equilibria, Prentice Hall, Englewood Cliffs, N. J., 1968.

24. R. C. Reid, J. M. Prausnitz and T. K. Sherwood, The Properties of Gases and Liquids, third ed., McGraw-Hill, New York, 1977.

25. S. V. Patankar and D. B. Spalding, Heat and Mass Transfer in Boundary Layers, 2nd Ed., Intertext Books, London, 1970. 


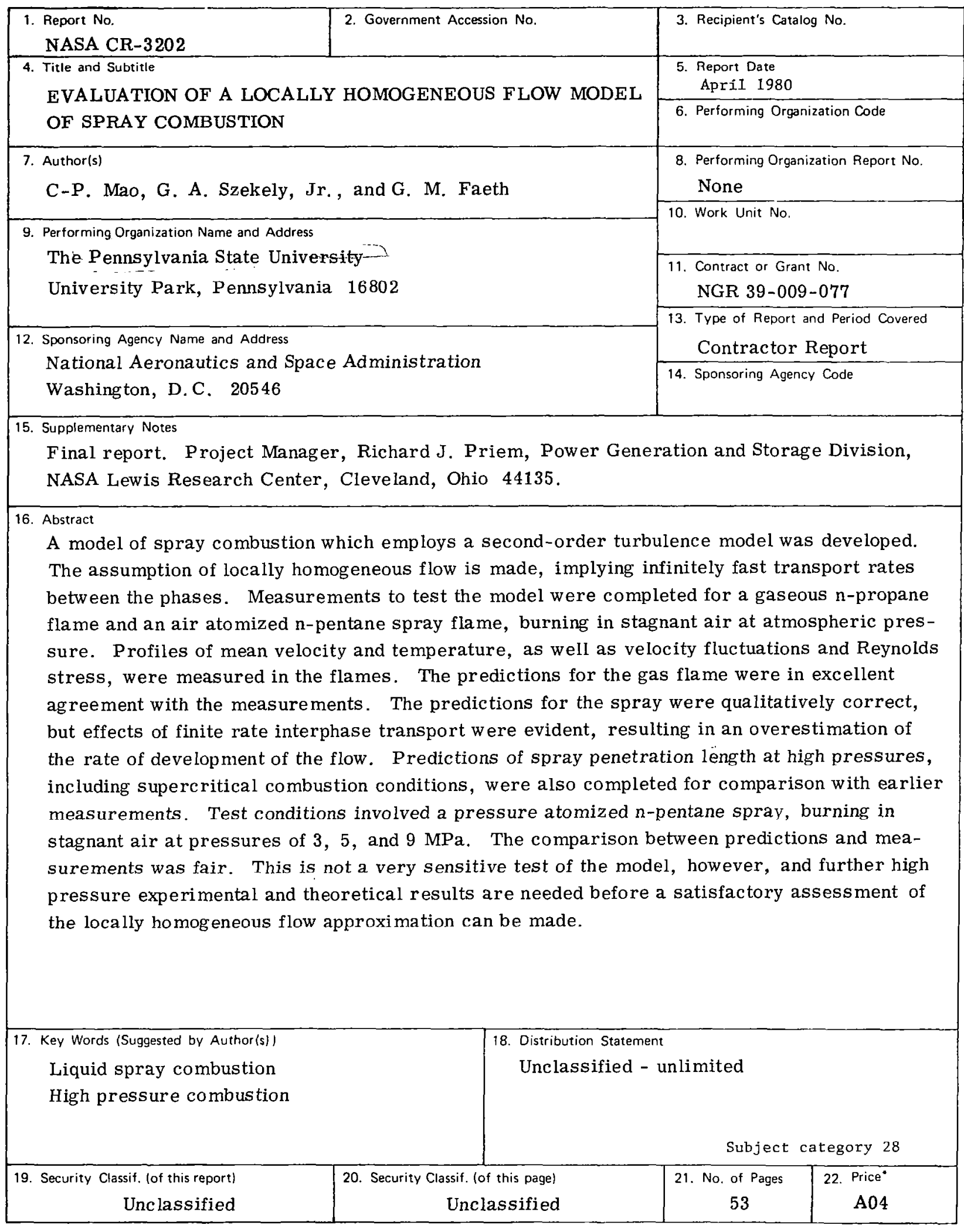

* For sale by the National Technical Information Service, Springfield, Virginia 22161 